\title{
The 1859 space weather event revisited: limits of extreme activity
}

\author{
Edward W. Cliver ${ }^{1, *}$ and William F. Dietrich ${ }^{2}$ \\ 1 Space Vehicles Directorate, Air Force Research Laboratory, Sunspot, NM 88349, USA \\ *Corresponding author: ecliver@nso.edu \\ 2 Praxis, Inc., Alexandria, VA 22303, USA
}

Received 4 April 2013 / Accepted 17 September 2013

\begin{abstract}
The solar flare on 1 September 1859 and its associated geomagnetic storm remain the standard for an extreme solar-terrestrial event. The most recent estimates of the flare soft X-ray (SXR) peak intensity and Dst magnetic storm index for this event are: SXR class $=\mathrm{X} 45( \pm 5)($ vs. X35 $( \pm 5)$ for the 4 November 2003 flare) and minimum $D$ st $=-900(+50,-150) \mathrm{nT}$ (vs. -825 to $-900 \mathrm{nT}$ for the great storm of May 1921). We have no direct evidence of an associated solar energetic proton (SEP) event but a correlation between $>30 \mathrm{MeV}$ SEP fluence $\left(\mathrm{F}_{30}\right)$ and flare size based on modern data yields a best guess $\mathrm{F}_{30}$ value of $\sim 1.1 \times 10^{10} \mathrm{pr} \mathrm{cm}^{-2}$ (with the $\pm 1 \sigma$ uncertainty spanning a range from $\sim 10^{9}-10^{11} \mathrm{pr} \mathrm{cm}^{-2}$ ) for a composite (multi-flare plus shock) 1859 event. This value is approximately twice that of estimates/measurements - ranging from $\sim 5-7 \times 10^{9} \mathrm{pr} \mathrm{cm}^{-2}-$ for the largest SEP episodes (July 1959, November 1960, August 1972) in the modern era.
\end{abstract}

Key words. space weather - extreme events - solar activity - magnetic storms - historical records

\section{Introduction}

In a quirk of history, the first observed solar flare, on 1 September 1859 (Carrington 1860; Hodgson 1860), was associated with arguably the largest space weather event ever recorded (Stewart 1861; Loomis 1859, 1860, 1861 (see Shea \& Smart 2006); Cliver 2006b). As reported by Cliver \& Svalgaard (2004), the Carrington event, as it is commonly called, was at or near the top of size-ordered lists of magnetic crochet amplitude, SEP fluence (McCracken et al. 2001a, 2001b), Sun-Earth disturbance transit time (Cliver et al. 1990), geomagnetic storm intensity (Tsurutani et al. 2003), and low-latitude auroral extent (e.g., Botley 1957; Vallance Jones 1992).

Increasing interest in extreme space weather events for both practical and theoretical reasons (e.g., Hapgood 2011, 2012; Vasyliunas 2011; Riley 2012; Schrijver et al. 2012; Aulanier et al. 2013) has led to re-examination of various aspects of the 1859 event, specifically flare size (Boteler 2006; Clarke et al. 2010), geomagnetic storm intensity (Siscoe et al. 2006; Li et al. 2006; Gonzalez et al. 2011), and SEP fluence (Wolff et al. 2012; Usoskin \& Kovaltsov 2012). In Section 2, the results of these and other studies are reviewed and new research is presented to reassess the observed/inferred upper limits of the size of the 1859 flare and the intensity of its effects. Conclusions are summarized and discussed in Section 3.

\section{Reappraisal of the 1859 solar-terrestrial event}

\subsection{Solar flare}

\subsubsection{Soft X-ray flare classification}

Cliver \& Svalgaard (2004) used the size of the magnetic crochet recorded on the Greenwich magnetograms for the 1859 flare (Fig. 1) as a gauge of the intensity of the flare SXR emission.
A magnetic crochet, or solar flare effect (SFE) in modern terms, is a type of sudden ionospheric disturbance (SID) caused by flare-induced enhancement of ionospheric E-region currents. Solar flares are commonly classified in terms of their Geostationary Operational Environmental Satellite (GOES) 1-8 peak SXR intensity. The classification system is defined as follows: classes $\mathrm{C} 1-9, \mathrm{M} 1-9$, and X1-9 correspond to flare peak 1-8 $\AA$ intensities of $1-9 \times 10^{-6}, 1-9 \times 10^{-5}$, and $1-9 \times 10^{-4} \mathrm{~W} \mathrm{~m}^{-2}$, respectively. (A flare with SXR intensity $=10(50) \times 10^{-4} \mathrm{~W} \mathrm{~m}^{-2}$ is designated X10 (X50).) From a comparison of the magnetometer H-component deflection at Greenwich for the Carrington event $(\Delta H=110 \mathrm{nT}$; onset at 11:18 UT) with the SFE amplitudes of modern large flares of known SXR intensity (Fig. 2), Cliver and Svalgaard "conservatively conclude[d] that the Carrington flare was a $>$ X10 SXR event" and suggested that it would have ranked high among the largest $\sim 100$ flares of the previous $\sim 150$ years.

The flare on 4 November 2003, generally considered to be the most intense SXR event during the space age, with an estimated peak SXR classification ranging from $\sim$ X25-45, ${ }^{1}$ occurred during the "Halloween" event sequence of flares (Gopalswamy et al. 2005a). The GOES 1-8 $\AA$ emission in this event saturated at an SXR classification of X17.4, but Kiplinger \& Garcia (2004) used $3 \mathrm{~s}$ SXR data to reconstruct the light curve - making reference to those of other flares with similar time profiles from the same active region - to estimate a peak classification of X30.6. Thomson et al. (2004, 2005) and

\footnotetext{
${ }^{1}$ The 1 June 1991 event (Kane et al. 1995; Tranquille et al. 2009) may have been comparable in intensity. The measured (estimated) saturation time above the X17.4 level was $\sim 13(\sim 10)$ min for 4 November 2003 (1 June 1991). Tranquille et al. place the 1 June event $\sim 15^{\circ}$ behind the east limb (for observation by GOES) implying occultation of the base of the SXR flare. The distance normalized $>25 \mathrm{keV}$ intensities measured by Ulysses were similar for both flares, neither of which was occulted at that satellite.
} 


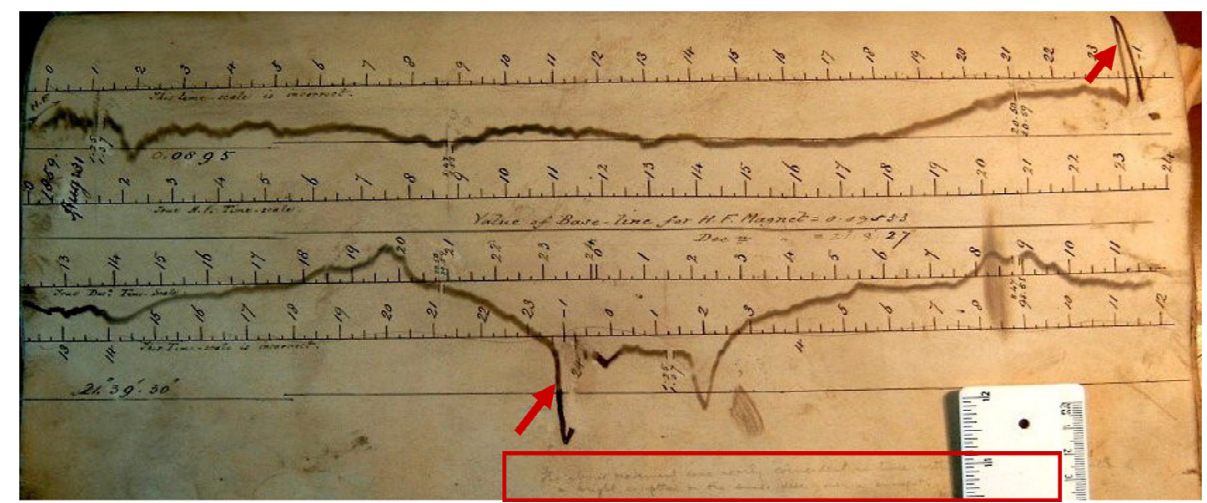

Fig. 1. Greenwich Observatory magnetometer traces (horizontal force on top and declination on the bottom; the two traces are offset by $12 \mathrm{~h}$ ) during the time of the solar flare on 1 September 1859. The red arrows indicate the magnetic crochet or SFE. The writing at the bottom in the red box says "The above movement was nearly coincidental in time with Carrington's observation of a bright eruption on the Sun. Disc[overed] over a sunspot. (H.W.N., 2 Dec 1938)". H.W.N. refers to Harold W. Newton, Maunder's successor as the sunspot expert at Greenwich. (From Cliver \& Keer 2012, with permission of Solar Physics.)

(a)

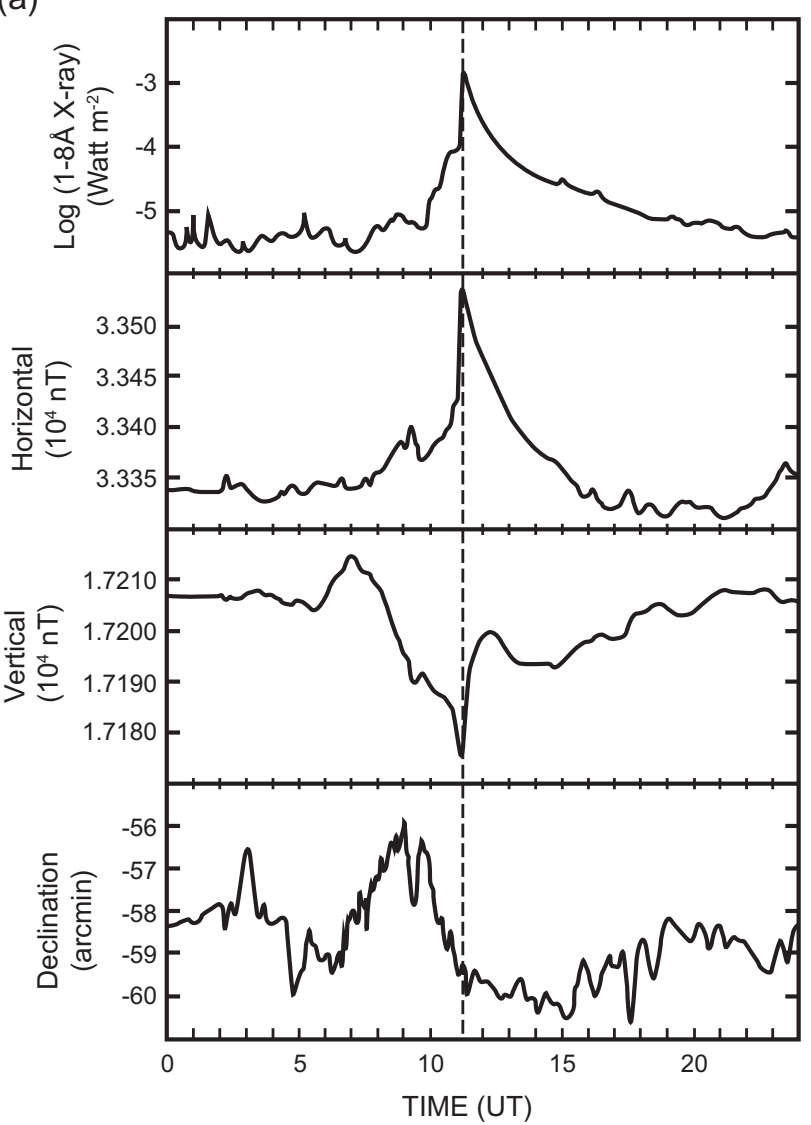

(b)

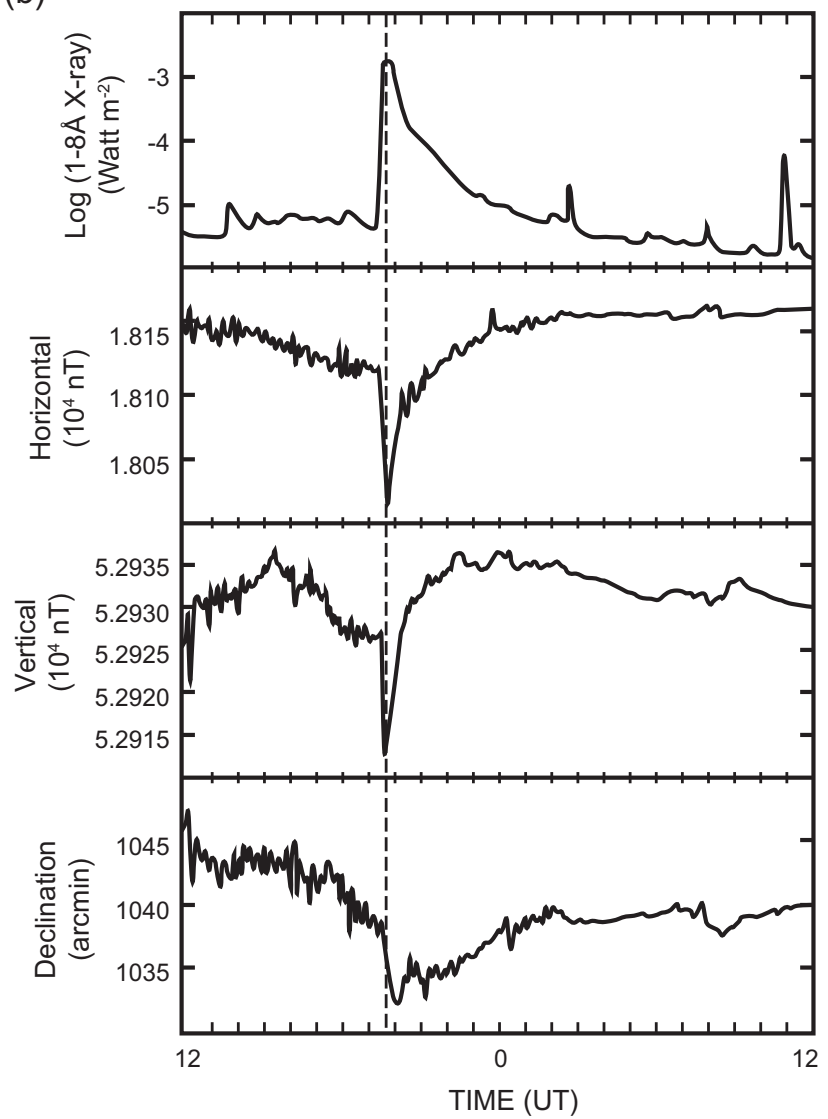

Fig. 2. Large (>100 nT) SFEs on (a) 28 October 2003, and (b) 4 November 2003. In each case, the associated SXR burst (top panel) is shown along with the magnetometer traces (bottom three panels). The vertical dashed lines are drawn at the peak of the SXR event. (From Cliver \& Svalgaard 2004, with permission of Solar Physics.)

Brodrick et al. (2005) analyzed SIDs for this flare to deduce peak SXR classifications of X $45 \pm 5$ (from sudden phase anomalies of VLF transmissions) and X34-X48 (from sudden HF cosmic noise absorption measured by riometers), respectively. From a comparison of GOES 1-8 $\AA$ and Ulysses $>25 \mathrm{keV}$ peak X-ray fluxes, Tranquille et al. (2009) deduced a SXR flare classification of $24.8 \pm 12.6$, consistent with the X30.6 determination of Kiplinger \& Garcia (2004). We take a mean value of X35 from the $\sim$ X25-45 range of estimates for the 4 November 2003 flare and assign an uncertainty of \pm 5 classification units, weighting the more direct assessment of Kiplinger \& Garcia (2004) higher than the SID-based estimates of Thomson et al. and Brodrick et al. Boteler (2006) noted that the SFE recorded at 11:15 local time for the 4 November flare at Victoria Magnetic Observatory in British Columbia (for which the geographic latitude of $48.5^{\circ} \mathrm{N}$ is similar to the 


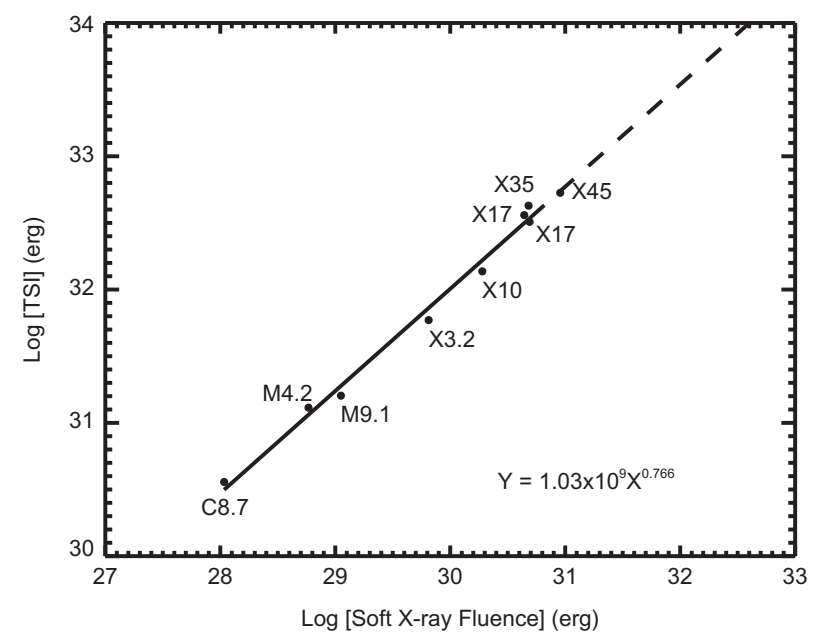

Fig. 3. Plot of the log of flare bolometric fluence vs. the log of the corresponding flare 1-8 $\AA$ SXR fluence. The data are taken from Kretzschmar (2011) and Emslie et al. (2012; we use X35 for the 4 November 2003 flare.) The regression line is a geometric mean least squares fit. The X45 event corresponds to the Carrington flare.

$51.5^{\circ} \mathrm{N}$ latitude of London) was $100 \mathrm{nT}(\Delta H)$ compared with the $110 \mathrm{nT}$ recorded at Kew (cf., Clarke et al. 2010) at the same local time for the 1859 event. This result indicates that the 1859 event was at least as large as the November 2003 flare. More recently, Clarke et al. (2010) determined the variations of the magnetic vector in the horizontal plane for $\sim 350$ observations of SFEs including those from Greenwich and Kew for 1859. From this analysis, they deduced that the SXR classification of the Carrington flare was no less than $\sim \mathrm{X} 15$ and more likely $\sim$ X42 (based on Greenwich (Kew) - derived classifications of X42 (X48)). From the Boteler and Clarke et al. studies, we adopt X45 $( \pm 5)$ as a working SXR classification for the great flare on 1 September 1859.

\subsubsection{Bolometric energy}

In another approach to determine the size of the largest possible solar flare, Schrijver et al. (2012) and Aulanier et al. (2013) determined the peak attainable bolometric energy based on the observed maximum areas and magnetic field strengths of solar active regions and an estimated magnetic energy conversion efficiency. Schrijver et al. (2012) suggested a maximum radiative energy release of $\sim 10^{33}$ erg while Aulanier et al. (2013) obtained a peak flare energy of $\sim 6 \times 10^{33}$ erg from a 3D MHD simulation for eruptive flares. For a sample of 38 large eruptive flares, Emslie et al. (2012) determined that, on average, flare bolometric energy was about one-third that of the kinetic energy of the associated coronal mass ejection (CME). In a key development, Kretzschmar et al. (2010, 2011) determined the relationship of the total solar irradiance (TSI) of flares to their SXR fluences. The TSI vs. SXR fluence correlation in Figure 3 is based on Kretzschmar's (2011) TSI and SXR values for four binned SXR classes (C8.7, M4.2, M9.1, and X3.2) and the bolometric and SXR fluences for four large $(\geq X 10)$ flares from Woods et al. (2006; re-evaluated by Emslie et al. 2012). Figure 5 in Veronig et al. (2002), which relates flare SXR fluence to SXR intensity (or classification), and Figure 3 indicate that a flare with bolometric energy of $10^{33}$ erg $\left(\sim 6 \times 10^{33} \mathrm{erg}\right)$ will correspond to a class $\sim \mathrm{X} 90$ $(\sim \mathrm{X} 700)$ SXR flare. A Carrington-class flare $(\sim \mathrm{X} 45)$ would have a radiative energy of $\sim 5 \times 10^{32}$ erg and a combined bolometric plus CME kinetic energy $\sim 2 \times 10^{33}$ erg. We stress, as did Schrijver et al. (2012), the uncertainty in the relationship in Figure 3 for large events. The upper part of the curve is based on only four events (X10-X35) for which the uncertainties in TSI range from $\pm 39 \%$ to $\pm 86 \%$ (Woods et al. 2006).

\subsection{Geomagnetic storm}

\subsubsection{The H-component reading of $-1600 \mathrm{nT}$ from Colaba on 2 September 1859 likely included an ionospheric contribution}

The horizontal $(\mathrm{H})$ trace from the Kew Observatory magnetogram (Stewart 1861; Bartels 1937), showing the magnetic crochet on 1 September and the early stages of the great magnetic storm that began $17.5 \mathrm{~h}$ later, is given in Figure 4 . The storm trace was driven off scale at Kew, as was also the case at Greenwich (Cliver \& Keer 2012). Thus until about 10 years ago, we had no good estimate of the size of the Carrington storm, although the off-scale recordings and the associated widespread aurora indicated that it was big. Then in 2003, Tsurutani et al. published long-neglected observations that were made at Colaba Observatory in Bombay (present-day Mumbai; geomagnetic latitude $=9.6^{\circ} \mathrm{N}$, ca. 1860), India. These observations did not go off scale because they were manually rather than automatically recorded. Tsurutani et al. (2003) used the $17.5 \mathrm{~h}$ transit time of the disturbance and various correlations to infer a minimum $D$ st of $-1760 \mathrm{nT}^{2}$ a value consistent with a sharp excursion in the Colaba H-trace of -1600 nT. A minimum $D$ st of $-1760 \mathrm{nT}$ indicates a storm approximately three times more intense than the next largest storm, the March 1989 event (minimum $D$ st $=-589 \mathrm{nT}$ ).

It has been difficult to model the Colaba-based Dst trace for the 1859 event. Figure 5 shows a reconstruction of the 2 September 1859 storm by Li et al. (2006) along with inferred solar wind parameters, e.g., peak solar wind speed $\left(V_{X}\right)$ and southward $B\left(-B_{\mathrm{Z}}\right)$ values of $1850 \mathrm{~km} \mathrm{~s}^{-1}$ and $-65 \mathrm{nT}$, respectively. Both of these values are in the realm of what has been observed in the past (e.g., Cliver et al. 1990, Temerin \& Li 2006). The magnetospheric storm model of Temerin \& $\mathrm{Li}$ (2002) used in Figure 5 has been proven successful in reproducing measured $D$ st from solar wind data for large magnetic storms (Temerin \& Li 2006) and for inferring solar wind parameters across coverage gaps in satellite data from geomagnetic observations (Cliver et al. 2009). In Figure 5, however, the most remarkable aspect of the 1859 storm is not how it got so big but rather its sharp recovery - driven by an extreme pressure pulse which compressed the magnetosphere (a sudden-commencement-type effect). The invoked density profile has a maximum hourly-averaged density of $\sim 1700 \mathrm{~cm}^{-3}, \sim 14$ times larger than any such value yet observed. The histogram in Figure 6 gives the probability distribution of all density $\left(N_{\mathrm{P}}\right)$ values observed from 1963 to the present. Following Siscoe et al. (1978), the histogram has been fitted with two exponentials, one for the main body of the distribution and one for the tail. Integrating the area under these curves and inverting yields an impossibly long recurrence interval of $\sim 10^{55}$ years for a $1700 \mathrm{~cm}^{-3}$ density event. Li et al. (2006) noted that the H-trace rose $\sim 1200 \mathrm{nT}$ in 20 min following its maximum

\footnotetext{
${ }^{2}$ The Dst (Disturbance storm time) geomagnetic index is a measure of the increase of the ring current during storms (Sugiura 1964; Mayaud 1980). It is based on measurements of the H-component of the field at four relatively low-latitude stations. Great storms with Dst $<-250 \mathrm{nT}$ occur on average about once per year (Cliver \& Crooker 1993; Zhang et al. 2007). Events with Dst $<-500 \mathrm{nT}$ occur approximately every 50 years $(1859,1909(?), 1921$, and 1989).
} 


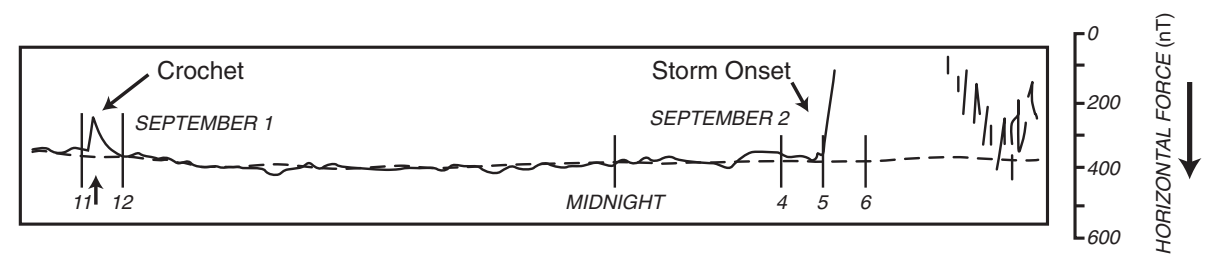

Fig. 4. The horizontal trace of the Kew magnetogram from 10:12 UT on 1 September 1859 to 10:10 UT on 2 September 1859 (after Stewart 1861 and Bartels 1937). The times of the prompt (magnetic crochet or solar flare effect) and delayed (geomagnetic storm onset) responses to the Carrington flare are indicated by arrows.
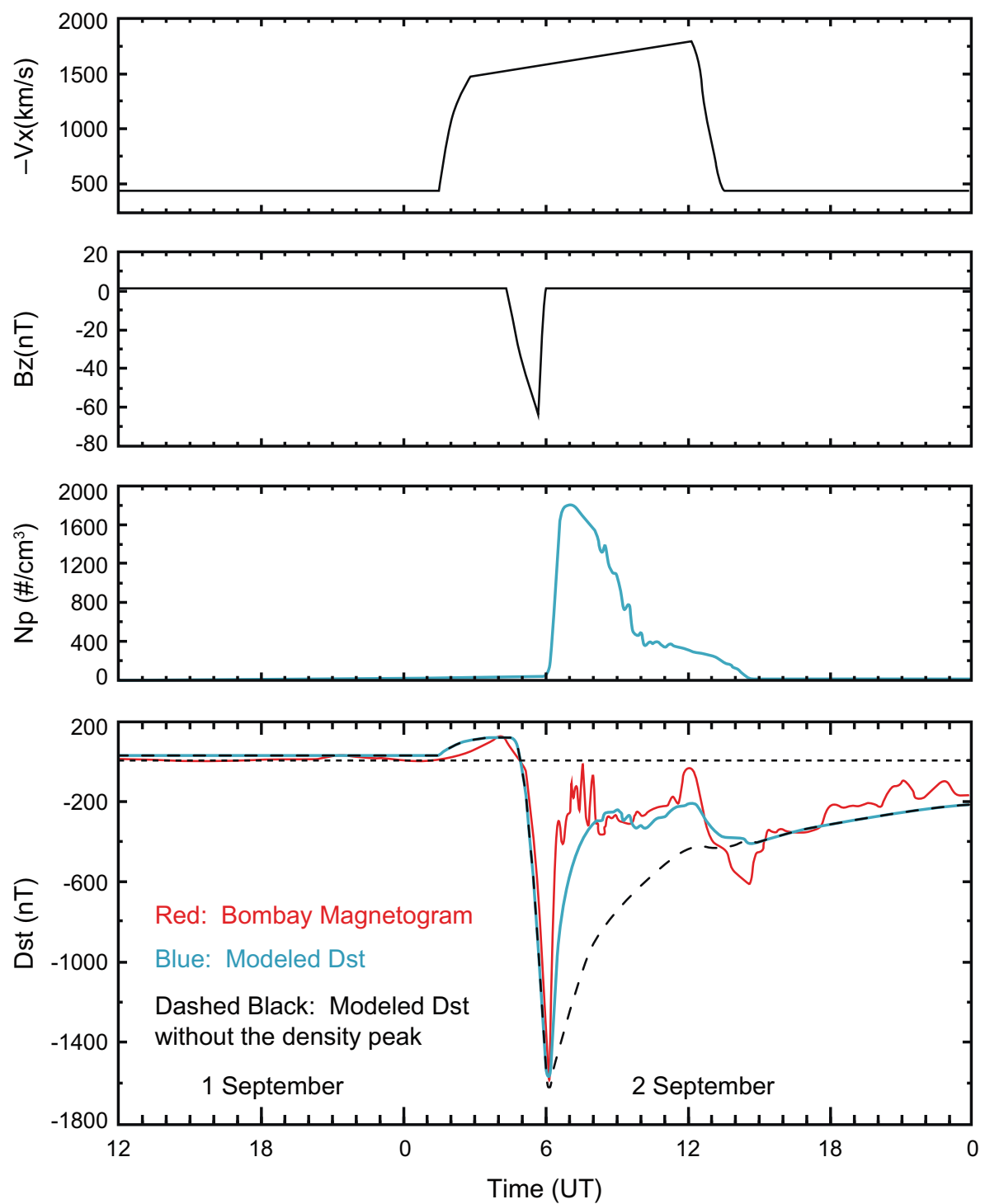

Fig. 5. Assumed solar wind parameters (every $10 \mathrm{~min}$; top three panels) and comparisons between modeled Dst (every $10 \mathrm{~min}$ ) and the H-component of the magnetometer record (every 15 min during the main phase and every 5-10 min during the recovery phase; bottom panel) made at the Colaba Observatory in Bombay (current day Mumbai) on 1-2 September 1859. (From Li et al. 2006, with permission from Elsevier.)

negative excursion and added that modeling the sharp recovery without the extreme density pulse would require a ring current decay constant of this order.

Because of the inferred size and rapid recovery of the deep negative excursion in the Colaba magnetogram, its reality as a magnetospheric, rather than an ionospheric, or combined magnetosphere-ionospheric, effect has been questioned (Akasofu \& Kamide 2005; Siscoe et al. 2006; Green \& Boardsen 2006; cf.,
Tsurutani et al. 2005). Figure 7, taken from Green \& Boardsen (2006), shows that the widespread aurora observed near local midnight in the American sector (5-6 UT; top panel) occurred during the time of the deep negative excursion in $H$ recorded at Colaba (bottom panel). From this combined figure, Green \& Boardsen (2006) concluded that "... the Bombay magnetometer was most likely measuring magnetic perturbations from currents in the nearby auroral electrojet and the magnetopause, in 


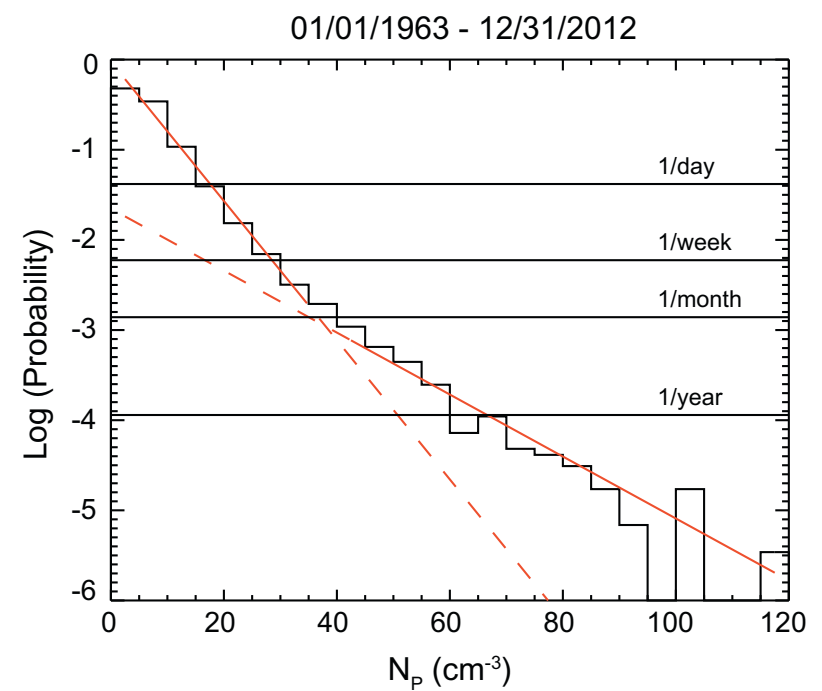

Fig. 6. Histogram of the occurrence frequency of hourly-averaged solar wind density values from 1963-present. The scale on the $y$-axis gives the probability that an entry selected at random from the entire data set will fall in a given density bin. The straight red lines are exponential fits to the main body and the tail of the distribution. Recurrence periods are indicated for various density values.

addition to the ring current, with the nearby auroral electrojet potentially dominating the measurements".

The inferred -1760 nT Dst value for the 1859 event has also been challenged on technical grounds. Siscoe et al. (2006) noted that standard $D$ st is an hourly-average index while the $-1600 \mathrm{nT}$ measurement from Colaba was a spot reading. Akasofu \& Kamide (2005) objected because standard Dst is based on observations from several stations widely distributed in longitude rather than from a single station.

The idea that the sharp and deep dip in the Colaba magnetogram was due, at least in part, to ionospheric/auroral currents, is indirectly supported by the H-trace record from Greenwich for a great storm on 24 October 1847 (Fig. 8; top panel) which is compared, at the same intensity and time scaling, with the $\mathrm{H}$ record at Colaba for the Carrington storm (bottom panel). As was the case at Colaba in 1859, the 1847 event was manually recorded and thus did not go off scale. The minimum H-reading at Greenwich at 22:04 UT ( $\Delta H=\sim-1100 \mathrm{nT})$ occurred during the observation of an auroral corona in southern England. From Greenwich, Glaisher (1847) reported "a magnificent display" between 21:57 and 22:04 UT. Challis (1847) described the corona as observed from Cambridge:

The most remarkable feature of the [aurora] was the distinct convergence of all the streamers towards a single point of the heavens ... Around this point a corona, or star-like appearance, was formed, the rays of which diverged in all directions from the center, leaving a space about the center free from light ... its azimuth was $18^{\circ} 41^{\prime}$ from $\mathrm{S}$. towards E., and its altitude $69^{\circ} 51^{\prime} \ldots$ this singular point was situated in, or very near a vertical circle passing through the magnetic pole [zenith] ... Had it not occurred in bright moonlight, the splendour of this display would probably have equaled any ever observed in this latitude.

Other examples where reported overhead aurora were associated with sharp deviations in the magnetometer record during great storms can be found under "Extraordinary Observations of Magnetometers" in the early Greenwich year books. Digitized records of such occurrences exist for storms on 25 October 1870, 9 April 1871, and 4 February 1872 (see Jones 1955 for accounts of the associated auroral observations).

The similarity in the H-component time-profiles for the 1847 and 1859 events in Figure 8, coupled with the auroral timing data for the 1859 event given in Figure 7, supports the assertion of Green \& Boardsen (2006). The similarity of the traces in Figure 8 is not meant to imply, however, that the two storms were of same size; the smaller decrease in $H$ at Greenwich for the 1847 storm ( - $1100 \mathrm{nT})$ compared with the $-1600 \mathrm{nT}$ observed at low-latitude Colaba in 1859 underscores the severity of the latter event.

The observation at Colaba of the sharp dip in $H$ was made near local noon (from 5:00 UT (onset) - 6:00 UT (minimum) - 6:30 UT (end); Fig. 5), precluding observation of a visual aurora. For this event, however, there is ample evidence of concomitant rapid and intense magnetic variations, characteristic of auroral activity, at higher latitudes. The most notable observation of such activity was made at Rome (geomagnetic latitude $=38.8^{\circ} \mathrm{N}$ ), where Secchi (1859) observed a decrease of $\sim 3000 \mathrm{nT}$ in $\mathrm{H}$. During or near the time of the H-decrease, there was a dramatic change in the declination (D), for which the timing is more clearly described as follows:

The next morning, on the 2 nd of September, at 7 a.m. [6:20 UT; presumably when the daily observations began], the magnets were extremely agitated ... At $7: 10$ [6:30 UT] the position of the declinometer was observed: extremely to the west, at $2^{\circ} 50^{\prime}$ beyond its usual position. From that moment the magnet returned quickly to the east until even exceeding the average position of $1^{\circ} 23^{\prime}$, reaching there at 7:30 [6:50 UT], thereby covering $4^{\circ} 13^{\prime}$ in less than half an hour. This disturbance is very surprising for us, the largest one observed until now was 45 to $50^{\prime}$.

Strong and rapid variations in $H$ were also observed in Ekaterinburg, Russia (geomagnetic latitude $=49.9^{\circ} \mathrm{N}$ ) from 05:42 to $\sim 7: 00 \mathrm{UT}$, during which time $H$ increased to $>500 \mathrm{nT}$ and decreased to $<-500 \mathrm{nT}$ (Tyasto et al. 2009).

The near-simultaneity of the sharp and strong variations at high-, mid-, and low-magnetic latitudes is illustrated in Figure 9. The initial rapid positive variation at Ekaterinburg (which went off scale at the levels of the horizontal bars) is clearly an auroral effect and since the reported negative excursion at Rome exceeds that at Colaba, it seems clear that it too is dominated by aurora. Following Green \& Boardsen (2006), we suggest that the $-1600 \mathrm{nT}$ reading at Colaba also has an auroral contribution.

Support for this viewpoint is provided by the model of Siscoe et al. (2006) for the 1859 storm (Fig. 10). Using the modified Burton et al. (1975) equation of O'Brien \& McPherron (2000), Siscoe et al. were only able to fit the Colaba trace (light blue curve) by discarding its extreme minimum point. This approach may be justified if the low reading was partly due to an ionospheric (auroral) current. Omitting the $-1600 \mathrm{nT}$ reading leaves a maximum negative $\mathrm{H}$-excursion of $\sim-1200 \mathrm{nT}$ and an hourly average of $\sim-625 \mathrm{nT}$, which agrees well with the middle, calculated hourly-averaged $D$ st (red) curve for B2 = $132 \mathrm{nT}$, where B2 = the value of the solar wind magnetic field strength at the leading edge of the CME. Siscoe et al. (2006) attribute the two-component storm observed at Colaba (Fig. 10) to "a southward IMF in the ICME-sheath 

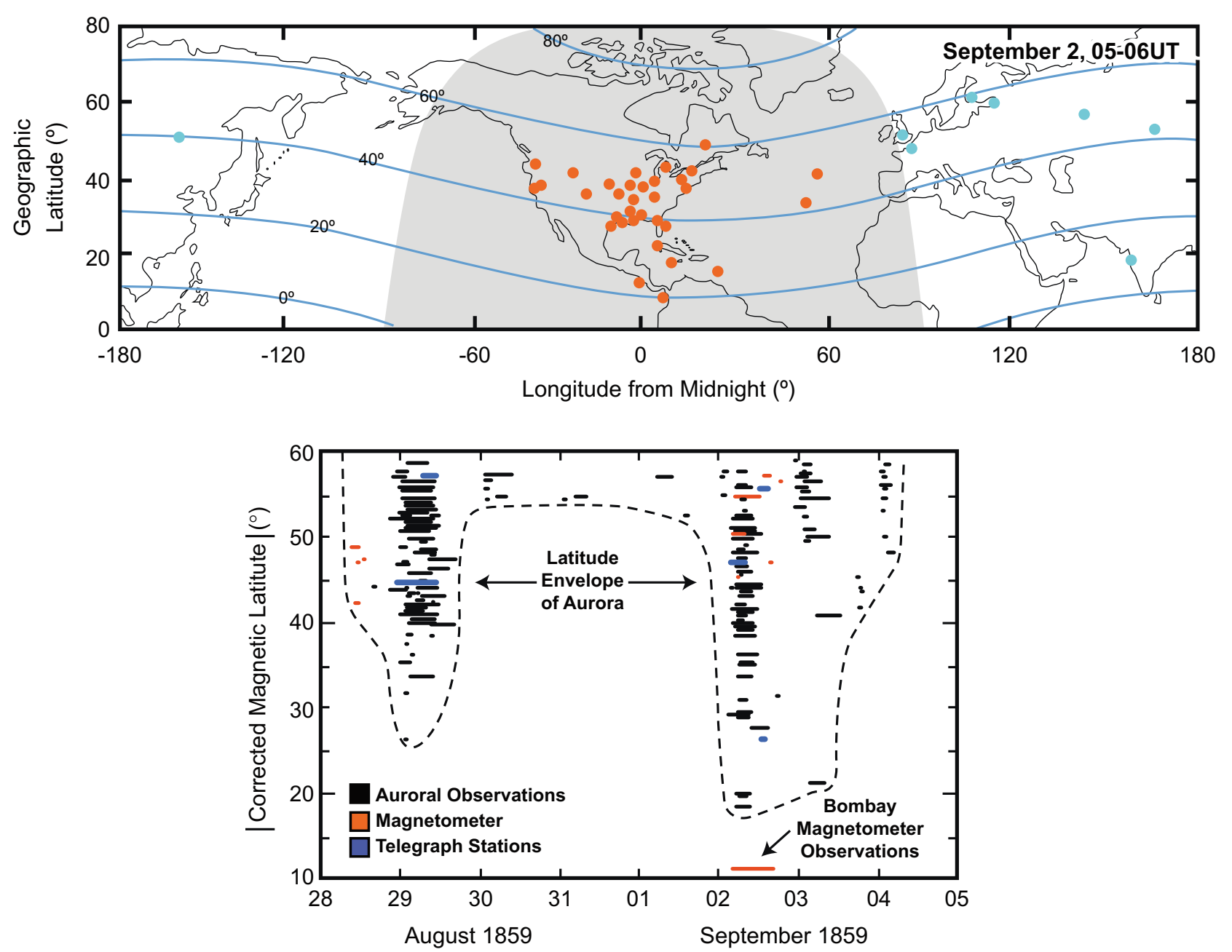

Fig. 7. (Top) Locations from which aurora were observed (orange points) or geomagnetic measurements were made (light blue points) during the peak of the great geomagnetic storm of 2 September 1859. Blue lines indicate geomagnetic latitude and gray shading indicates local night time. (Bottom) Latitude vs. time envelope of auroral observations (black lines), magnetometer records (orange), and telegraph disturbances (blue) for the 28 August and 2 September magnetic storms in 1859. The horizontal orange line at the bottom of the figure gives the timing of the September magnetic storm as observed at Colaba, near Bombay (now Mumbai) in India. (Adapted from Green \& Boardsen 2006, with permission from Elsevier.)

followed by a north-then-south rotation of the IMF as the ICME cloud swept over the earth ..." In this scenario, the inferred strong sheath fields suggest compression of the fields of a preceding CME (cf., Tsurutani et al. 2003). Given the two major storms on 28 August and 2 September, it is likely that the Sun (specifically the Carrington region) produced other large CMEs during this interval. Alternatively, Li et al. (2006) formally modeled the secondary minimum of $\sim 600 \mathrm{nT}$ at $\sim 14: 30$ on 2 September in the Colaba magnetogram by varying the solar wind density and speed (with $B_{\mathrm{S}}$ set equal to 0 ).

Siscoe et al. (2006) obtained an hourly-averaged Colaba Hcomponent minimum of $\sim-850 \mathrm{nT}$ (with no points excluded). More recently, Gonzalez et al. (2011) measured an hourly-averaged minimum $H$ of $-1050 \mathrm{nT}$ from the Colaba record and calculated an hourly-averaged value of $-1160 \mathrm{nT}$ following the approach of Tsurutani et al. (2003). Given the wide spread in these various determinations (empirical values from -850 to $-1050 \mathrm{nT}$; modeled values from -625 to $-1160 \mathrm{nT}$ ), we take the average of the reported values to obtain $\sim-900 \mathrm{nT}$ as our working estimate of the minimum $D$ st value of the Carrington storm, with a range from -850 to -1050 given by the empirical determinations.

\subsubsection{Comparison of various aspects of the September 1859 and May 1921 magnetic storms}

Siscoe et al. suggest that their analysis in Figure 10, including the omission of the extreme point in the Colaba record, "might retrieve the 1859 storm from [being] ... a singularity in a class by itself - and place it instead in the regular population of magnetic storms arranged as the end member in order of strength". The storm which comes closest to our working estimate of the strength of the Carrington storm is the 14-15 May 1921 event for which the minimum $D$ st value has been estimated to be $\sim-825$ to -900 nT (J. Love, personal communication, 2012; Kappenman 2006). Here we show that other aspects of the 1921 storm - auroral extent, technological effects, and source active region on the Sun - had similarities with the 1859 event.

\subsubsection{Low-latitude aurora}

The May 1921 storm is distinguished by the lowest-latitude (credible) observation ever made of an aurora (cf., Silverman 2008), from Apia, Samoa (13.83 S $171.75^{\circ} \mathrm{W} ; 15.3^{\circ} \mathrm{S}$ geomagnetic latitude, ca. 1920; Angenheister \& Westland 1921). For comparison, the lowest geomagnetic latitude from which 
E.W. Cliver \& W.F. Dietrich: The 1859 space weather event

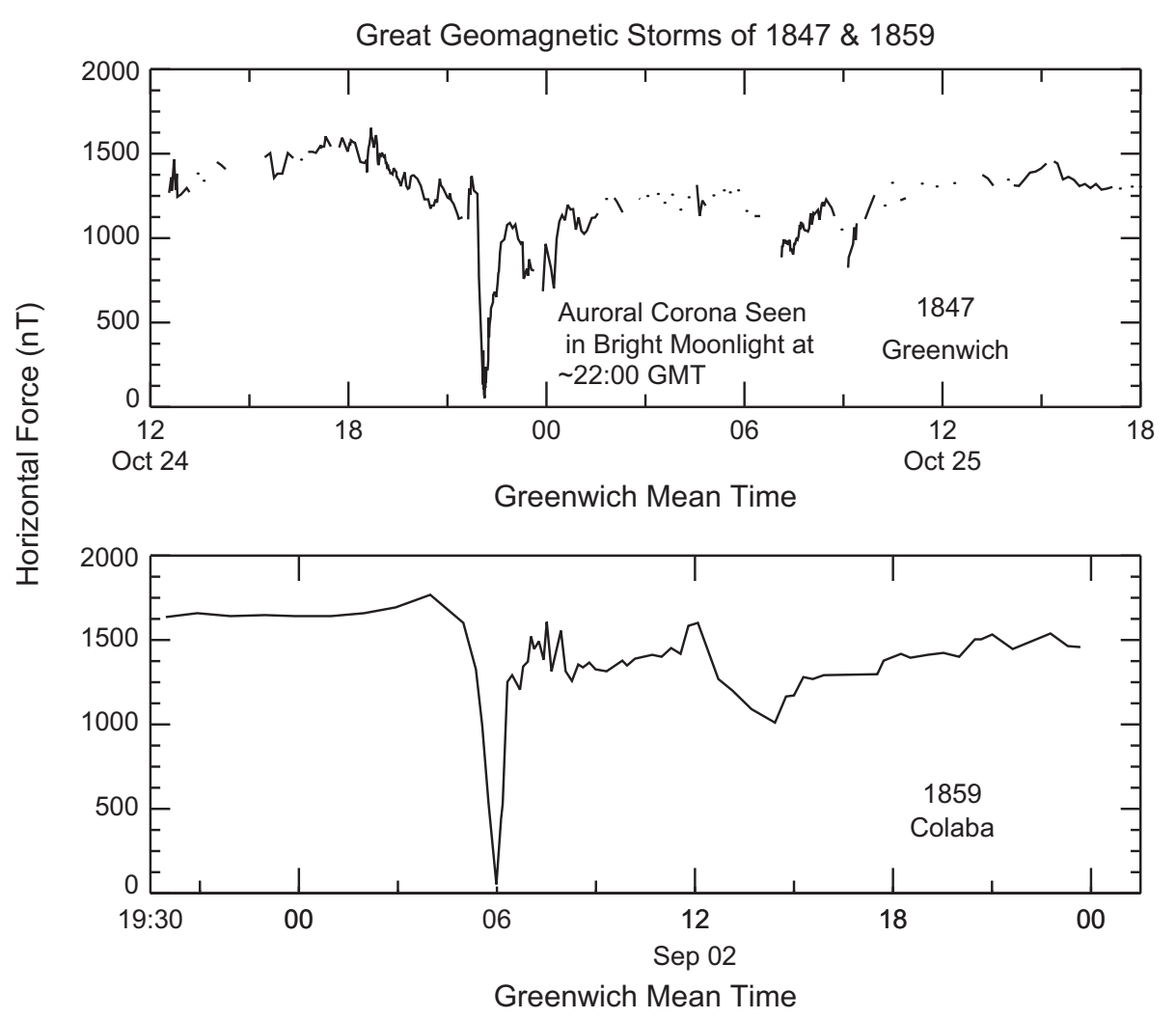

Fig. 8. Comparison of great magnetic storms observed at Greenwich in October 1847 (top panel) and at Colaba in September 1859 (bottom). The H-component magnetic intensity and time scales are the same in both plots. The peak of the 1847 storm coincided with an aurora observed in bright moonlight in southern England.

the September 1859 aurora was observed was $\sim 18^{\circ}$ (Green \& Boardsen 2006). At Apia, on 15 May 1921, Angenheister and Westland reported an auroral arc that spanned $\sim 25^{\circ}$ in the southern skies from 5:45 to 6:30 UT [6:15-7:00 p.m. local time]. The arc, "of a glowing red colour", was centered approximately on the magnetic meridian and had a peak altitude of $22^{\circ}$. They noted that, "The point of the greatest intensity appeared to move from east to west at about $6 \mathrm{~h} 20 \mathrm{~m}$. Greenwich time ..." and that no signs of the light were seen after 6:30 UT. Angenheister \& Westland (1921) reported that the aurora was also observed in the southern skies from Tongatapu $\left(21.21^{\circ} \mathrm{S} ; 175.15^{\circ} \mathrm{W} ; 23.8^{\circ} \mathrm{S}\right.$ geomagnetic). Assuming a top altitude of $\sim 800 \mathrm{~km}$ for a low-latitude aurora (Loomis 1861; see Smart \& Shea, p. 374 ff.), the 1921 event would have been overhead at a geographic latitude of $\sim 27^{\circ} \mathrm{S}$ (geomagnetic latitude of $\sim 31^{\circ} \mathrm{S}$ ). The Angenheister and Westland reports of these low-latitude sightings are puzzling, however, because observers in Auckland, New Zealand $\left(36.84^{\circ} \mathrm{S} 174.74^{\circ} \mathrm{E}\right.$; $42.4^{\circ} \mathrm{S}$ geomagnetic), who first noticed the aurora "just after dusk" at $\sim 6$ UT, did not report aurora to the north (Silverman \& Cliver 2001). The reports from Auckland indicate that at the peak of the disturbance, the aurora filled the southern sky from horizon to zenith, with no mention of an extension to the north. An aurora extending $800 \mathrm{~km}$ above the earth's surface at $27^{\circ} \mathrm{S}$ geographic on the $180^{\circ}$ meridian that runs approximately through Apia, Tongatapu, and Auckland, should have been visible at an altitude $28^{\circ}$ above the northern horizon from Auckland, but was not reported. ${ }^{3}$ At minimum, this indicates

\footnotetext{
${ }^{3}$ An aurora of $\sim 600 \mathrm{~km}$ peak height would have been overhead at $\sim 25^{\circ} \mathrm{S}$ geographic $\left(\sim 29^{\circ} \mathrm{S}\right.$ geomagnetic $)$ and visible at an altitude of $16^{\circ}$ above the northern horizon from Auckland.
}

that the aurora in the southern hemisphere was not continuous in latitude, or as Westland (1921) put it, "It may be that we in Samoa and our fellowmen in New Zealand were not looking at the same thing". Such an implied gap in the 1921 aurora was observed in ultraviolet by Dynamics Explorer 1 for the great March 1989 storm (Fig. 11, taken from Allen et al. 1989).

In the northern hemisphere, detailed and authoritative reports from Tucson (39.3 ${ }^{\circ} \mathrm{N}$ geomagnetic) and Flagstaff $\left(42.4^{\circ} \mathrm{N}\right.$ geomagnetic) in Arizona highlighted the extent of the 1921 aurora, including a corona, in the southern skies (Douglass 1921; Russell 1921; Slipher 1921; Lampland 1921; excerpted by Silverman \& Cliver 2001). From Tucson, Douglass reported that at a time "shortly after" 5:30 UT [10:30 p.m. local time], "renewed activity, especially in long lines extending over large parts of the sky ... and all pointing toward a vanishing point about $30^{\circ}$ south of the zenith [corresponding to the $60^{\circ}$ dip of the compass needle at Tucson] and a little to the west of the meridian, which is in the direction of our lines of magnetic force extending toward the South Pole". This sighting and a report of the aurora from the S.S. Hyades in the northern Pacific $\left(146.7^{\circ} \mathrm{W}, 33.3^{\circ} \mathrm{N}\right.$ geographic; $34.3^{\circ} \mathrm{N}$ geomagnetic; Silverman \& Cliver 2001) suggest that in the northern hemisphere the equatorward extent of the overhead aurora on 14-15 May 1921 came within a few degrees of that for the September 1859 aurora. For the 1859 event, Loomis (1861; see Shea \& Smart 2006, p. 374 ff.) used triangulation to determine that the southern margin of the aurora would have been overhead at a geographic latitude of $\sim 21.5^{\circ} \mathrm{N}$ in Cuba, corresponding to a geomagnetic latitude of $\sim 31^{\circ} \mathrm{N}$.

During the 05:45-06:30 UT interval that Angenheister and Westland reported the 1921 aurora from Apia, a positive bay of 

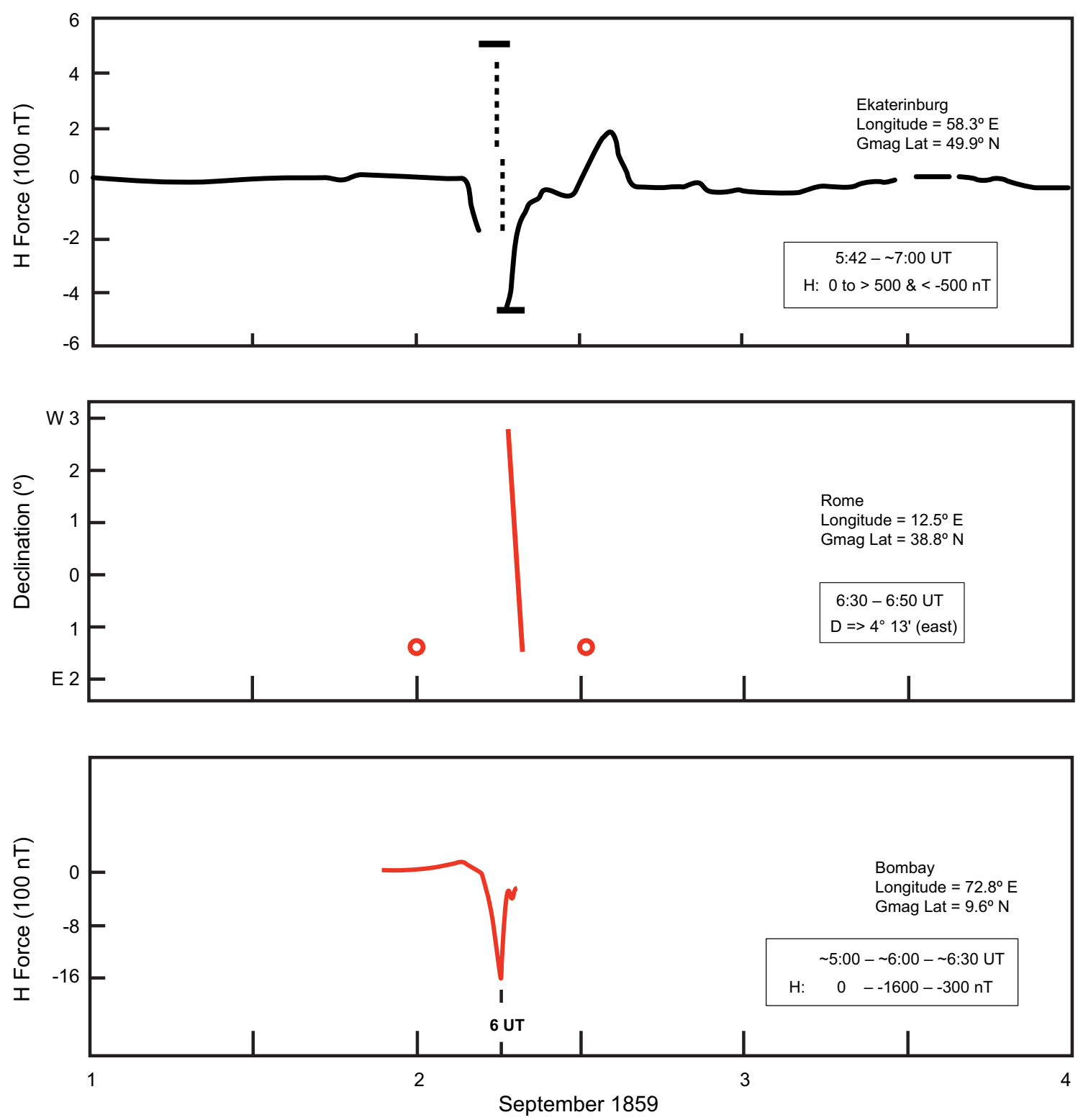

Fig. 9. Near simultaneous sharp and intense variations in magnetometer traces at stations spanning a broad range of magnetic latitudes during the 2 September 1859 storm: (top panel) H-component variation at Ekaterinburg; (middle) D-component variation at Rome; (bottom) $\mathrm{H}$-component variation at Colaba. The horizontal bars in the top panel represent levels at which traces went off scale; the dashed lines indicate the successive abrupt positive and negative excursions. The open orange circles in the second panel indicate the normal declination at Rome. Geomagnetic latitudes are for epoch 1860 .

$\sim 400 \mathrm{nT}$, indicated by the oval in Figure 12, rose and fell sharply on a time scale characteristic of an auroral effect. This close timing association of the positive bay and the auroral arc provides direct support for the reality of auroral effects at low latitudes in great magnetic storms. The red arc observed by Angenheister and Westland was part of a global aurora, occurring at the same time (6 UT) that Russell, observing from Flagstaff, noted that the whole southern sky was illuminated.

Both the 1859 and 1921 storms had their peak intensity near $\sim 6$ UT, approximately midnight in Chicago. Thus the auroral electrojet in the Samoan sector in 1921 would be flowing eastward resulting in a diminution of negative $H$ - as observed while that in the Indian sector in 1859 would be flowing westward resulting in an enhancement of negative $H-$ as inferred.

\subsubsection{Technological effects}

Both the September 1859 event and May 1921 storms were the cause of significant disruption of telegraph services (Boteler 2006; Silverman \& Cliver 2001). The Loomis (1859, 1860, 1861) articles (see Shea \& Smart 2001) link the 1859 storm to two cases of severe electrical shocks as well as to fires. These reported fires are reviewed by Loomis on p. 377 of the Shea \& Smart (2006) compendium:

During the auroras of Aug. 28th and Sept. 2d, paper and even wood were set on fire by the auroral influence alone. (In the following, only the 2 September storm is considered.) ... At Springfield, Mass., the heat was sufficient to cause the smell of scorched wood and paint to 


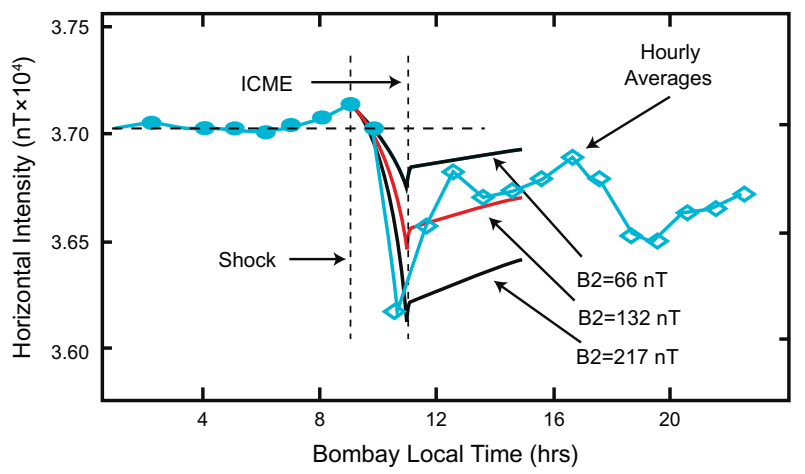

Fig. 10. Calculated hourly Dst values (black and red solid lines) for the 1859 storm for different assumed values of solar wind $B(\mathrm{~B} 2)$ at the leading edge of the CME. The light blue line is the hourlyaveraged Colaba $H$-trace, with the dashed horizontal black line giving the pre-event baseline. The dashed vertical lines indicate the assumed arrival time of the shock and the leading edge of the driving interplanetary CME. (Adapted from Siscoe et al. 2006, with permission from Elsevier.)

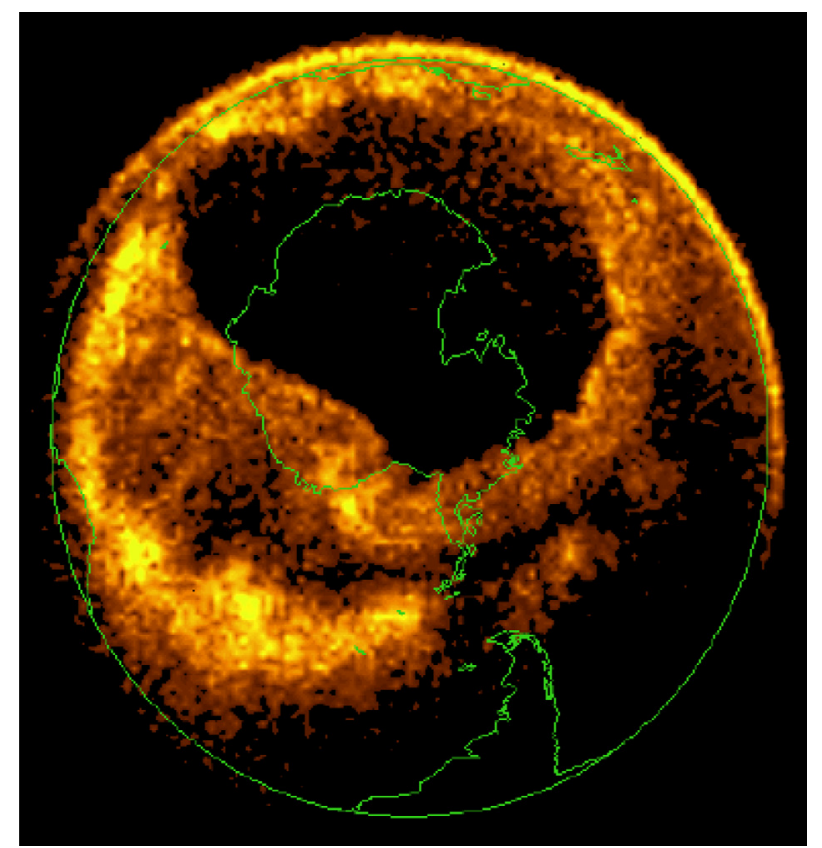

Fig. 11. Southern hemisphere aurora observed in ultra-violet by Dynamics Explorer 1 during the great magnetic storm in March 1989. The image was taken at 01:51 UT on 14 March. Note the rift in the aurora south of Antarctica (outlined in green) in the bottom half of the figure. [Adapted from Allen et al. 1989, with permission of John Wiley \& Sons, Inc.]

be plainly perceptible. (A report of a paper fire in Boston in this review refers to a storm on 19 February 1852, not the 2 September 1859 storm (p. 328 of Shea \& Smart 2006).) On the telegraph lines of Norway, pieces of paper were set on fire by the sparks of the discharges from the wires ..." In addition, at Baltimore, Maryland, the telegraph operator reported (p. 361 of Shea \& Smart 2006) that "The intensity of the spark at the instant of breaking the circuit was such as to set on fire the wood work of the switch board".

The 1921 storm also was accompanied by fires, reportedly more severe than those in 1859. Excerpting from the 17 May 1921 edition of the New York Times:
"The disturbance was reported by cable to have burned out a telephone station in Sweden. ${ }^{4}$ It may have contributed to a short circuit in the New York Central signal system, followed by a fire in the Fifty-seventh street signal tower [which, quoting a Times story on May 16, left "the residents of many Park Avenue apartment houses ... coughing and choking from the suffocating vapors which spread for blocks".]

Brewster, N.Y., May 16. - A fire which destroyed the Central New England Railroad station, here, Saturday night, was caused by the Aurora Borealis, in the opinion of the railroad officials. Telegraph Operator Hatch says he was driven away from his instrument by a flare of flame which enveloped the switchboard and ignited the building. The loss was $\$ 6,000$.

It is clear that the fires for the 1921 storm (involving three separate buildings) surpassed those of 1859 (one scorching incident, one paper fire (possibly more), and one wood work fire) that are often emphasized in the popular secondary literature. As pointed out by one of the referees, however, a comparison of the technological effects of these storms - including fires requires a more detailed description/analysis of the affected telegraph systems (including the length and geographic distribution of circuits and the grounding systems used), which would have changed considerably between 1859 and 1921 .

\subsubsection{Associated solar active region}

The maximum area of the sunspot group associated with the May 1921 storm (1709 millionths of a solar hemisphere (msh)) was comparable to that for September 1859 (2300 msh) (Jones 1955). Lundstedt (2012) drew attention to the complexity and evolution of region 9934 in May 1921 and noted that, "Very strong magnetic flux density between $+3.4 \mathrm{kG}$ and $-3.5 \mathrm{kG}$ was measured by [Mount Wilson]".

\subsection{Solar energetic proton (SEP) event}

\subsubsection{The Carrington event did not leave a detectable SEP signal in ice core nitrates}

McCracken et al. (2001a, 2001b) used nitrate concentrations in an ice core from Summit, Greenland (GISP2 H) to extend the post-1950 record of omnidirectional $>30 \mathrm{MeV}$ SEP event fluences $\left(\mathrm{F}_{30}\right)$ back in time to 1561 . In their analysis, the inferred $\mathrm{F}_{30}$ value for the 1859 proton $(\mathrm{pr})$ event $\left(1.9 \times 10^{10} \mathrm{pr} \mathrm{cm}^{-2}\right)$ was $\sim 70 \%$ larger than that of the next biggest event $\left(1.1 \times 10^{10} \mathrm{pr} \mathrm{cm}^{-2}\right.$ in 1895$)$. For comparison, the largest SEP event in the satellite era, in August 1972, had a $F_{30}$ fluence of $5.0 \times 10^{9} \mathrm{pr} \mathrm{cm}^{-2}$ (Shea \& Smart 1990). ${ }^{5}$ The time series of historical SEP event fluences obtained by McCracken et al.

\footnotetext{
${ }^{4}$ The station was located in Karlstad; damages were estimated at 200,000 kronor, which exceeded the amount of 177,000 kronor on the (lapsed) insurance policy. (From http://www.tjugofyra7.se/msb/ Arkiv/Avdelningar/Nyheter/Svar-solstorm-drabbade-Karlstad-1921/; 20 April 2012.)

${ }^{5}$ Based on Solar-Geophysical Data, No. 342, Pt 2, p. 88, we obtained an $\mathrm{F}_{30}$ value of $8.2 \times 10^{9} \mathrm{pr} \mathrm{cm}^{-2}$ (see also Reedy 1977) for the combined events of 4 and 7 August 1972 (predominately from 4 August). The lower value of $5.0 \mathrm{pr} \mathrm{cm}^{-2}$ from Shea \& Smart (1990) for the combined 2, 4, and 7 August events is due to various corrections (e.g., for electron contamination) that those authors applied to the data (Smart et al. 2006a; D. Smart, personal communication, 2013).
} 


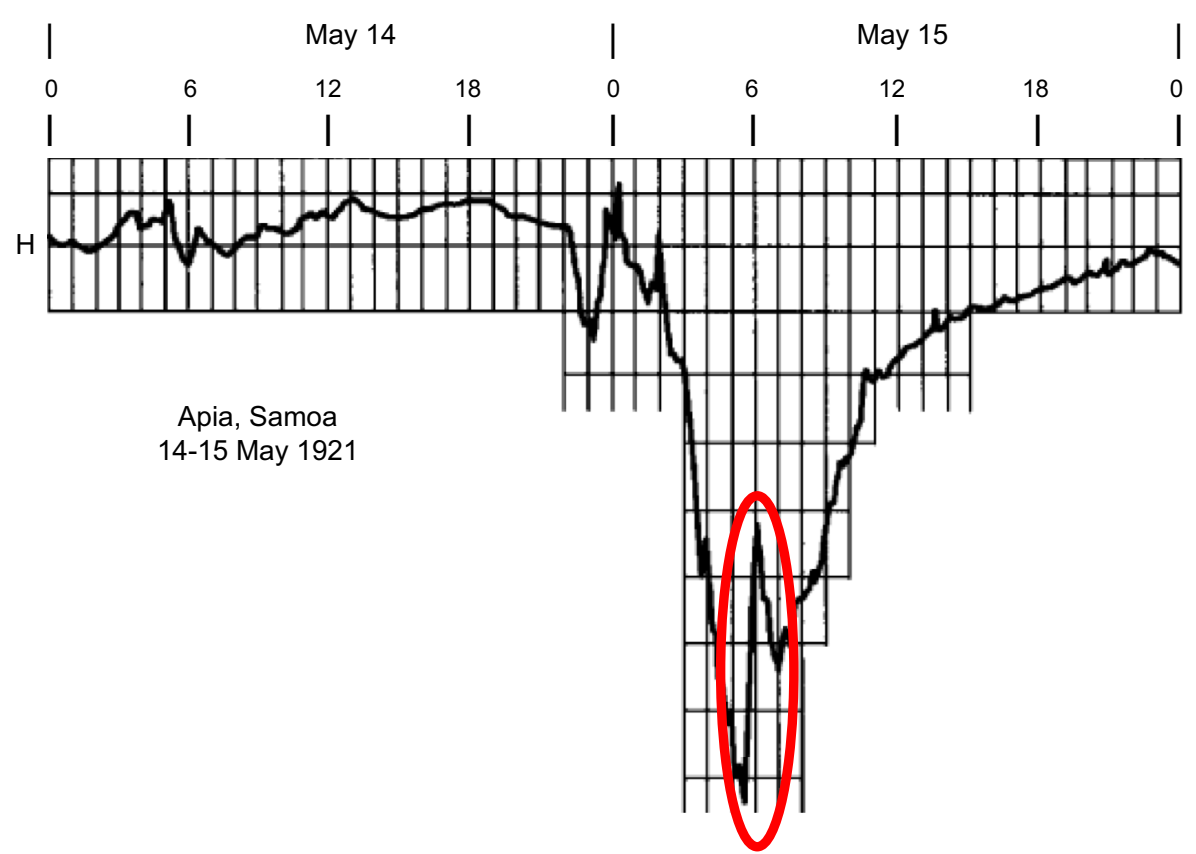

Fig. 12. The H-component of the magnetic storm of 14-15 May 1921 as recorded by Angenheister \& Westland (1921) at Apia, Samoa. The red oval encompasses a positive bay in the H-component magnetogram that was coincident with the observation of a rare low-latitude aurora. The chart is marked in Universal Time. [Adapted from Silverman \& Cliver 2001, with permission from Elsevier.]

promised to be a powerful tool with which to statistically probe worst case scenarios for SEP events. Unfortunately, this was not to be the case. In International Space Science Institute (ISSI) workshops held in September 2011 and April 2012 (Schrijver et al. 2012), it was shown that the nitrate peak in 1859 in the GISP2 $\mathrm{H}$ core was not present in ice cores from Antarctica or in other cores from Greenland (Wolff et al. 2012). Not only were Wolff et al. (2012) unable to substantiate the 1859 event in other cores, they attributed a nitrate spike they found close to 1859 (in 1863) in other cores from Greenland to biomass burning events (forest fires in North America) and suggested that the 1859 event in the GISP2 H core was incorrectly dated. Wolff et al. wrote, "It seems certain that most spikes in [GISP2 $\mathrm{H}]$, including that claimed for 1859 , are also due to biomass burning plumes, and not to solar energetic particle (SEP) events". They concluded that "an event as large as the Carrington Event did not leave an observable, widespread imprint in nitrate in polar ice. Nitrate events cannot be used to derive the statistics of SEPs".

\subsection{2. ${ }^{10}$ Be concentration in ice cores and SEP activity in 1859}

Usoskin \& Kovaltsov (2012) calculated the ${ }^{10} \mathrm{Be}$ signal that would be left in ice cores by a SEP event with an $\mathrm{F}_{30}$ fluence of $\sim 2 \times 10^{10} \mathrm{pr} \mathrm{cm}^{-2}$, such as that inferred by McCracken et al. (2001a, 2001b) for the 1859 event. Because cosmogenic isotopes (Beer et al. 2012) are produced by the most energetic part $(>430 \mathrm{MeV} ;>1 \mathrm{GV}$ in rigidity) of the SEP spectrum, Usoskin \& Kovaltsov (2012) chose the hard-spectrum SEP event of 23 February 1956 as their reference (referred to as SPE56, for Solar Proton Event 1956). For this event ground level neutron monitors registered a $>4500 \%$ increase (Cliver et al. 1982) vs. a relatively modest $1.0 \times 10^{9} \mathrm{pr} \mathrm{cm}^{-2} \mathrm{~F}_{30}$ increase inferred from high-latitude ionospheric measurements (Shea \& Smart 1990). In contrast, the soft spectrum event of 1972 August 4 (SPE72) produced only a $\sim 10 \%$ increase above background on neutron monitors (with $\mathrm{F}_{30} \sim 5 \times 10^{9} \mathrm{pr} \mathrm{cm}^{-2}$ ).

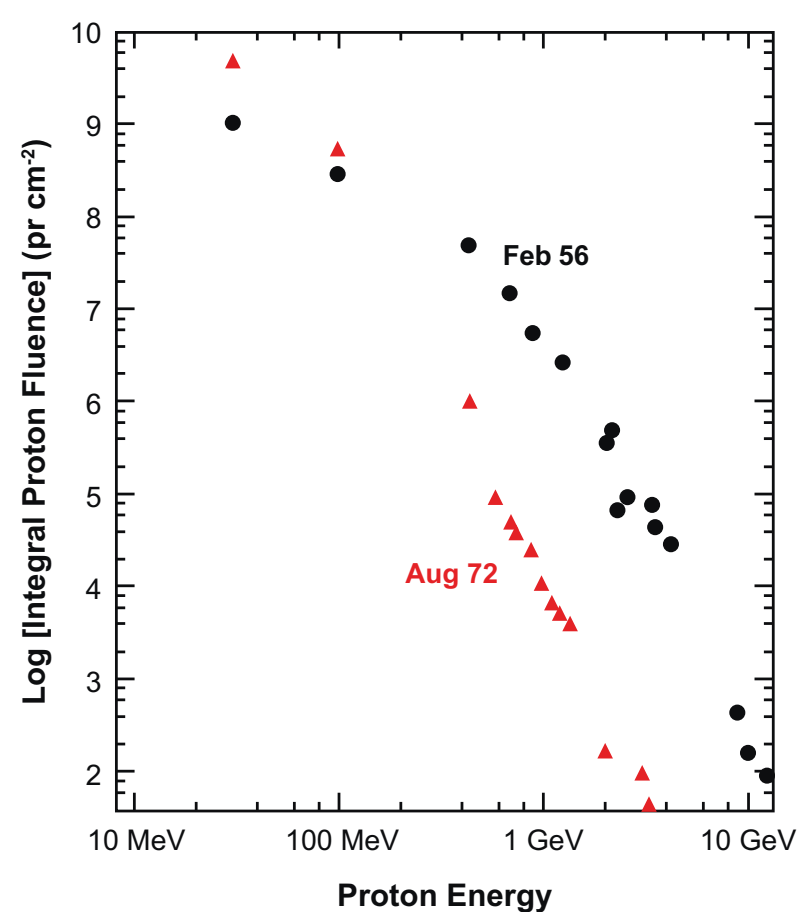

Fig. 13. Absolute integrated-fluence spectra (Tylka \& Dietrich 2009) of two high-energy SEP events considered by Usoskin \& Kovaltsov (2012) as reference spectra for the analysis of ${ }^{10} \mathrm{Be}$ signals of SEP events in ice cores: black - GLE on 23 February 1956, red GLE on 4 August 1972.

Integral SEP spectra for both the February 1956 and August 1972 events, obtained following the procedure outlined in Tylka \& Dietrich (2009), are shown in Figure 13. Usoskin \& Kovaltsov (2012) noted that, "An SPE72-type soft event would require a 40 times larger $\mathrm{F}_{30}$ [i.e., $\sim 8 \times$ SPE72], with respect to SPE56, to produce the same amount of cosmogenic isotopes. 
Accordingly, the $\left[\mathrm{F}_{30}\right]$ estimates obtained with the reference SPE56 spectrum should be enhanced 40-fold to correspond to a soft-spectrum SPE72 scenario". Since an SPE56 spectrum will produce a $\mathrm{F}_{30}$ fluence of $1.0 \times 10^{9} \mathrm{pr} \mathrm{cm}^{-2}$, Usoskin \& Kovaltsov used a $20 \times$ SPE56 spectrum to replicate the $F_{30}$ value of $1.88 \times 10^{10} \mathrm{pr} \mathrm{cm}^{-2}$ from McCracken et al. (2001a). For this $20 \times$ SPE56 scenario, they calculated ${ }^{10} \mathrm{Be}$ concentrations of $\sim 1.5$ and $\sim 2.5 \times 10^{4}$ at/g above background for two separate Greenland ice cores. No such signal was detected near 1859 for either core, leading Usoskin and Kovaltsov to conclude that a strong $\left(\mathrm{F}_{30}\right.$ value of $\left.>2 \times 10^{10} \mathrm{pr} \mathrm{cm}^{-2}\right)$ proton flare associated with the 1 September 1859 flare was not supported by the ${ }^{10} \mathrm{Be}$ data.

$\mathrm{A} \mathrm{F}_{30}$ value of $\sim 2 \times 10^{10} \mathrm{pr} \mathrm{cm}^{-2}$ can also be reproduced by a $4 \times$ SPE72 spectrum (vs. $20 \times$ SPE56). In this case, however, the ${ }^{10} \mathrm{Be}$ concentration calculated from the $20 \times$ SPE56 used by Usoskin \& Kovaltsov (2012) must be reduced by a factor of $40 \quad[(20 \times 8) / 4]$, leaving a signal of only $\sim 0.05 \times 10^{4} \mathrm{at} / \mathrm{g}$ due to the hypothesized Carrington event, well within the typical annual uncertainties $(\sim 0.2-0.5 \times$ $\left.10^{4} \mathrm{at} / \mathrm{g}\right)$ in the two ${ }^{10} \mathrm{Be}$ ice cores that were considered. Thus an $\mathrm{F}_{30}=\sim 2 \times 10^{10} \mathrm{pr} \mathrm{cm}^{-2} \mathrm{SEP}$ event in August/September 1859 cannot be ruled out, provided it had a soft spectrum.

In the modern era, the largest $>30 \mathrm{MeV}$ SEP events (with $\mathrm{F}_{30}$ values $\geq 4 \times 10^{9} \mathrm{pr} \mathrm{cm}^{-2}$ ) tended to originate in sequences of strong eruptive flares encompassing solar central meridian (Smart et al. 2006b). These composite events include July 1959 with flares on the 10th (located at E63), 14th (E07),

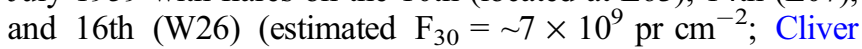
et al. 2013); November 1960 with flares on the 12th (W04) and 15th (W35) $\left(\sim 5 \times 10^{9} \mathrm{pr} \mathrm{cm}^{-2}\right.$; Cliver et al. 2013); August 1972 with flares on the 2nd (E34 and E28), 4th (E08), and 7th (W37) $\left(5.0 \times 10^{9} \mathrm{pr} \mathrm{cm}^{-2}\right)$, and October 1989 with flares on the 19th (E09), 22nd (W32), and 24th (W57) $\left(4.3 \times 10^{9} \mathrm{pr} \mathrm{cm}^{-2}\right)$. The only single-peaked SEP event with $\mathrm{F}_{30} \geq 4 \times 10^{9} \mathrm{pr} \mathrm{cm}^{-2}$ in the satellite era was the Bastille Day event in 2000 (W07; $4.3 \times 10^{9} \mathrm{pr} \mathrm{cm}^{-2}$ ). Even here, however, there were preceding large eruptive flares and minor SEP activity that may have contributed to the major SEP event on 14 July via seed particle creation (e.g., Cliver 2006a) and/or proton trapping (Kallenrode \& Cliver 2001). A class 3 flare at E30 on 10 November 1960 may have similarly contributed to the large event on 12 November (Steljes et al. 1961). Thus it appears that a series of eruptions from near solar central meridian is the preferred way for the Sun to produce a large $F_{30}$ SEP event. Because of the $>1$-year residence time of ${ }^{10} \mathrm{Be}$ in the stratosphere (Heikkilä et al. 2009), it would be difficult to separate closely-spaced SEP events in ice core data. Central meridian eruptive flares have characteristically softer SEP spectra than well-connected (W30-60) events (Van Hollebeke et al. 1975) and can exhibit shock spikes in their SEP time intensity profiles (Cane et al. 1988), as was the case for the 4 August 1972, 19 October 1989, and 14 July 2000 events. The shock peak from the 19 October 1989 SEP event (E09; Lario and Decker 2002) is indicated by the red arrow in Figure 14.

\subsubsection{Space age data can be used to provide a rough estimate of SEP fluence for the 1859 event}

Despite the absence of direct evidence from either nitrates or ${ }^{10} \mathrm{Be}$ for a large SEP event in early September 1859, there can be little doubt that the Carrington flare was associated with a major SEP event by modern standards. From the $17.5 \mathrm{~h}$ separation between the flare and the geomagnetic storm sudden

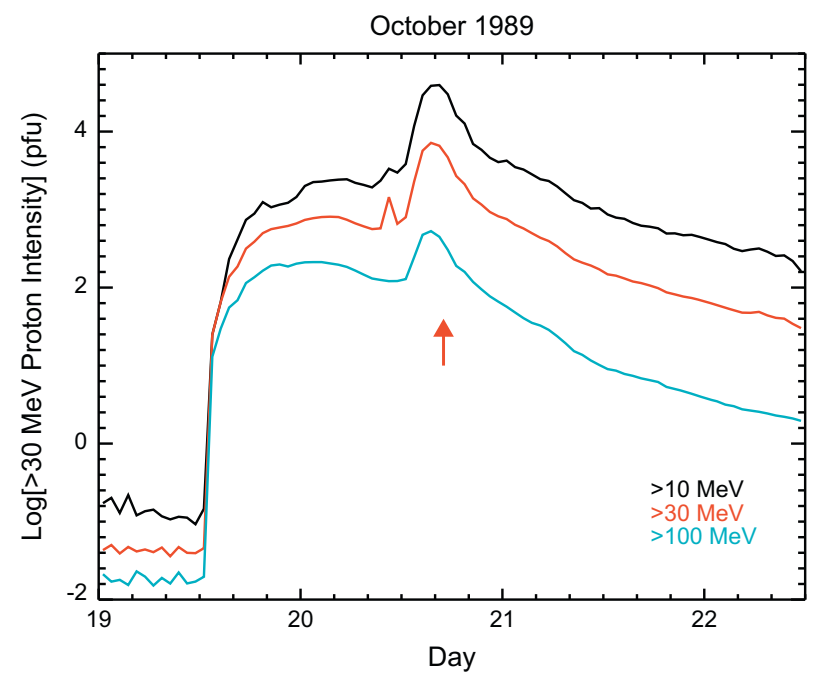

Fig. 14. GOES proton observations (at $>10 \mathrm{MeV},>30 \mathrm{MeV}$, and $>100 \mathrm{MeV}$ ) for the SEP event on 19 October 1989, showing the softer spectrum of the delayed shock peak at $\sim 16$ UT on 20 October, in comparison with the earlier broad prompt peak at $\sim 4$ UT. The arrow indicates a possible shock at $\sim 17$ UT in the solar wind data (Cliver et al. 1990).

commencement for this event, Gopalswamy et al. (2005b) estimated the associated CME to have an average near-Sun speed of $2356 \mathrm{~km} \mathrm{~s}^{-1}$. Using the list from Yashiro et al. (2006; http://cdaw.gsfc.nasa.gov/pub/yashiro/flare_cme/fclist pub.txt) for the Large Angle Spectroscopic Coronagraph (Brueckner et al. 1995) on SOHO, we find that the six CMEs with linear speeds $>2000 \mathrm{~km} \mathrm{~s}^{-1}$ that were associated with central meridian (within $\pm 25^{\circ}$ vs. $+12^{\circ}$ for the Carrington flare) flares from 1996 to 2005 were all followed by SEP events recorded by GOES that had peak $>10 \mathrm{MeV}$ fluxes in the range from $\sim 10^{2}$ to $5 \times 10^{3}$ pfu (where 1 pfu $=1$ proton flux uni$\mathrm{t}=1 \mathrm{pr} \mathrm{cm}^{-2} \mathrm{~s}^{-1} \mathrm{sr}^{-1}$ ) vs. a Space Weather Prediction Center threshold of $10 \mathrm{pfu}$ for a significant event. The dates of the flares for these events were: 10 April 2001, 24 September 2001, 28 October 2003, 29 October 2003, 15 January 2005, and 17 January 2005. Two of these events, both of which included shock peaks, had $\mathrm{F}_{30}$ values $\geq 10^{9} \mathrm{pr} \mathrm{cm}^{-2}: 24$ September $2001\left(1.2 \times 10^{9} \mathrm{pr} \mathrm{cm}^{-2}\right)$ and 28 October 2003 $\left(3.1 \times 10^{9} \mathrm{pr} \mathrm{cm}^{-2}\right)$. A recent "backside" example of a SEP event of this type occurred on 23 July 2012 (Mewaldt et al. 2013; Russell et al. 2013). The flare was located near "central meridian" (W12 relative to STEREO A) and had a CME speed of $2003 \mathrm{~km} \mathrm{~s}^{-1}$. The estimated $>30 \mathrm{MeV}$ fluence, including a strong shock peak, is $\sim 2 \times 10^{9} \mathrm{pr} \mathrm{cm}^{-2}$.

Similarities between the 4 August 1972 and 1 September 1859 eruptive flares suggest that their associated SEP events also had similar characteristics. Both flares were located close to central meridian (N14E08 for 1972 and N20W12 for 1859). As was the case for the 1972 event, the 1859 flare was presumably part of a sequence of events from a given active region. A great magnetic storm that began on 28 August 1859 implies an eruption early on August 27 when the region that produced the Carrington flare was located at E55-60 (Cliver 2006b). Finally, both the 4 August 1972 and 1 September 1859 flares were associated with an inferred fast CME (transit time to Earth of $17.5 \mathrm{~h}$ vs. $14.6 \mathrm{~h}$ for August 1972; Cliver et al. 1990). Using 4 August 1972 as one of their reference SEP events, Smart et al. (2006a) modeled the 


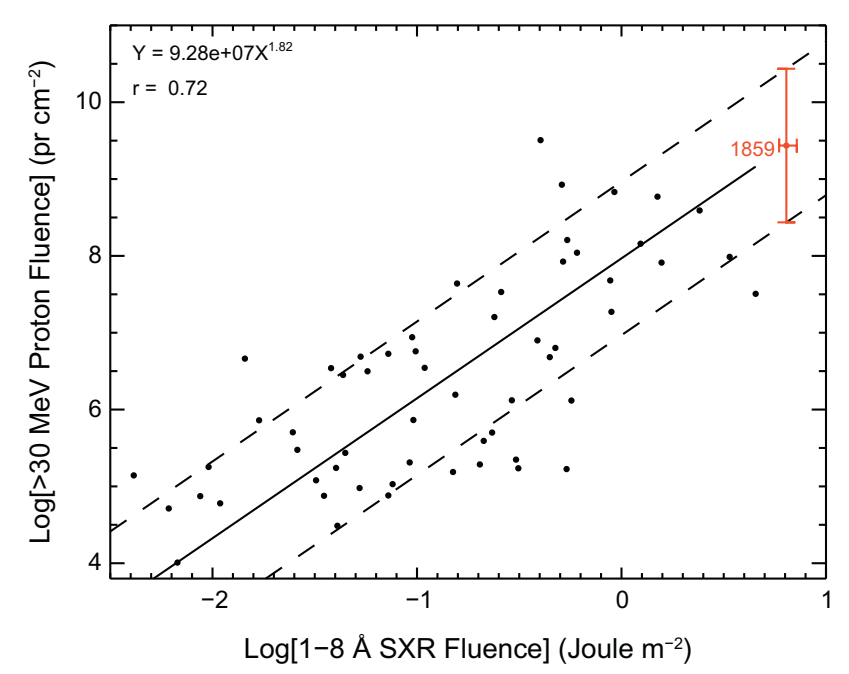

Fig. 15. Scatter plot of $\mathrm{F}_{30}$ vs. flare 1-8 $\AA$ fluence for prompt proton events originating from W20 to W85 heliolongitude (1996-2005; Cliver et al. 2012), with geometric mean power law regression line, for which the equation and correlation coefficient are given. The geometric mean regression line fit was used because the parameters are not thought to be causally related; both are attributed to a fast CME which leads to reconnection and a flare in its wake while driving a shock responsible for the SEP event. The dashed lines are drawn at $\pm 1 \sigma$ and the position of the 1859 event is indicated.

1 September 1859 SEP event as a soft-spectrum event with a shock spike.

Modern observations can provide some quantitative guidance on the size of the 1859 SEP event. Figure 15 is a scatter plot of $\mathrm{F}_{30}$ vs. 1-8 $\AA$ SXR fluence for all proton events from 1996 to 2005 that were associated with flares with nominally good (W20-W85) magnetic connection to Earth (taken from Table 2 in Cliver et al. 2012; SEP events with hourly-averaged peak $>10 \mathrm{MeV}$ fluxes $\geq 1 \mathrm{pfu}$ ). The equation for the regression line, with correlation coefficient, is given in the figure. The dashed lines in Figure 15 indicate the $\pm 1 \sigma$ uncertainty range. SEP (and SXR fluence) integrations began with flare onset and typically were ended, if possible, at the $10^{-1} \mathrm{pfu}$ level on the decay of the $>30 \mathrm{MeV}$ proton event (excepting times of elevated backgrounds or when a large SXR/SEP event occurred before background was reached). SXR integrations were ended at the $\mathrm{C} 2$ level (for events with starting fluxes $\geq \mathrm{C} 1$ ) or at $\mathrm{C} 1$ (for events with starting fluxes $<\mathrm{C} 1$ ). Backgrounds taken at the lower of the flux levels of the start and end times were subtracted for both SXR and SEP events. Significant SXR bursts superimposed on the time profile of the source flare were excised in the SXR fluence determinations. The proton fluence values shown in the plot are for the prompt components of the SEP events; shock peaks (see Fig. 14) were excluded for three cases (22 November 2001, 28 May 2003, 25 July 2004). Taking X45 as the peak SXR intensity of the Carrington flare and determining the corresponding SXR fluence $\left(6.4 \mathrm{~J} \mathrm{~m}^{-2}\right)$ via Figure 5 in Veronig et al. (2002), we obtain a nominal $F_{30}$ value of $2.7 \times 10^{9} \mathrm{pr} \mathrm{cm}^{-2}$ for the Carrington flare. This does not include allowance either for additional eruptive flares or for a shock peak.

To gauge the contribution from these additional components of a composite SEP event, we considered in Figure 16 the three largest $F_{30}$ events for which we have satellite measurements (August 1972, October 1989, and July 2000). In each of these cases in Figure 16 we determined $F_{30}$ for: (1) the first major SEP event in the series, or, in the case of July 2000, the only major SEP event (light blue cross-hatching), omitting the contribution from any associated shock spike (in order to obtain the prompt component), (2) the shock spike (red crosshatching), and (3) the contribution from any closely following SEP events (purple cross-hatching). We obtained the following values for the ratios of the total omnidirectional $\mathrm{F}_{30}$ for a composite (multi-flare plus shock) event to that of the principal component (excluding the shock peak) of the initial event in each sequence: August 1972 (ratio = 4.0; 8.24/2.08 (composite event total $\mathrm{F}_{30}$; black number in each panel of Fig. 16$) /\left(\mathrm{F}_{30}\right.$ of initial event minus shock contribution; light blue number)), October 1989 (3.7; 4.28/1.15), and July 2000 (1.2; 4.33/ 3.67). For a "worst case scenario", we use a factor of 4 (rounding up the ratio of the October 1989 event for which the shock component is most the clearly defined) to adjust the nominal prompt component value of $\mathrm{F}_{30}=2.7 \times 10^{9} \mathrm{pr} \mathrm{cm}^{-2}$ for a $\mathrm{X} 45$ flare to $\sim 1.1 \times 10^{10} \mathrm{pr} \mathrm{cm}^{-2}$, with a corresponding $\pm 1 \sigma$ uncertainty range from $\sim 10^{9}$ to $\sim 10^{11} \mathrm{pr} \mathrm{cm}^{-2}$. The $\sim 1.1 \times$ $10^{10} \mathrm{pr} \mathrm{cm}^{-2}$ estimate is approximately twice that of the $\sim 5-7 \times 10^{9} \mathrm{pr} \mathrm{cm}^{-2}$ range of peak $\mathrm{F}_{30}$ values observed for compound events during the modern era.

\section{Conclusion}

\subsection{Summary}

In response to new research on the 1859 solar-terrestrial event since the survey by Cliver \& Svalgaard (2004), we updated our assessment of this remarkable event. In the intervening years, the estimate of the size of the flare has been refined from "conservatively $>$ X10" to $\sim \mathrm{X} 45( \pm 5)$, with bolometric flare energy $\sim 5 \times 10^{32}$ ergs (and bolometric plus CME kinetic energy of $\sim 2 \times 10^{33}$ ergs). Estimates of the Dst minimum of the associated magnetic storm have drifted downward from $-1760 \mathrm{nT}$ to $\sim 900 \mathrm{nT}(+50,-150)$, based on hourly-averaging of the Colaba record and the likelihood of auroral contamination. The estimate for the $>30 \mathrm{MeV}$ SEP fluence of $\sim 1.9 \times$ $10^{10} \mathrm{pr} \mathrm{cm}^{-2}$ for the Carrington event deduced from nitrate composition in ice cores has been invalidated (Wolff et al. 2012). A nominal value of $\mathrm{F}_{30}=1.1 \times 10^{10} \mathrm{pr} \mathrm{cm}^{-2}$ was obtained for an X45 event (in a "worst case" scenario for a sequence of eruptive flares) by using a correlation between $\mathrm{F}_{30}$ and SXR flare fluence for space-age events. The $\pm 1 \sigma$ uncertainty band on this $\mathrm{F}_{30}$ value is large, ranging from $\sim 10^{9}$ to $\sim 10^{11} \mathrm{pr} \mathrm{cm}^{-2}$.

\subsection{Discussion}

While the new estimates for flare size and storm intensity for the 1859 space weather event are at the top of their respective categories, both have close, essentially equal, competitors, given the uncertainties involved. Size estimates for the 4 November 2003 super-flare are: SXR classification of $\sim \mathrm{X} 35( \pm 5)$ and, from Emslie et al. (2012), a flare bolometric energy of $\sim 4 \times 10^{32}$ ergs and a total (bolometric plus CME kinetic energy) of $\sim 10^{33}$ ergs. The evidence seems strong that the great magnetic storm on 14-15 May 1921 (Kappenman 2006) was comparable to the 1859 event, with both having Dst intensities -900 nT, approximately 50\% larger than the March 1989 storm.

One aspect of the geomagnetic storm in 1859 warrants special mention - the indication championed by Green \& Boardsen (2006) that the sharp dip in the Colaba H-trace had a significant 

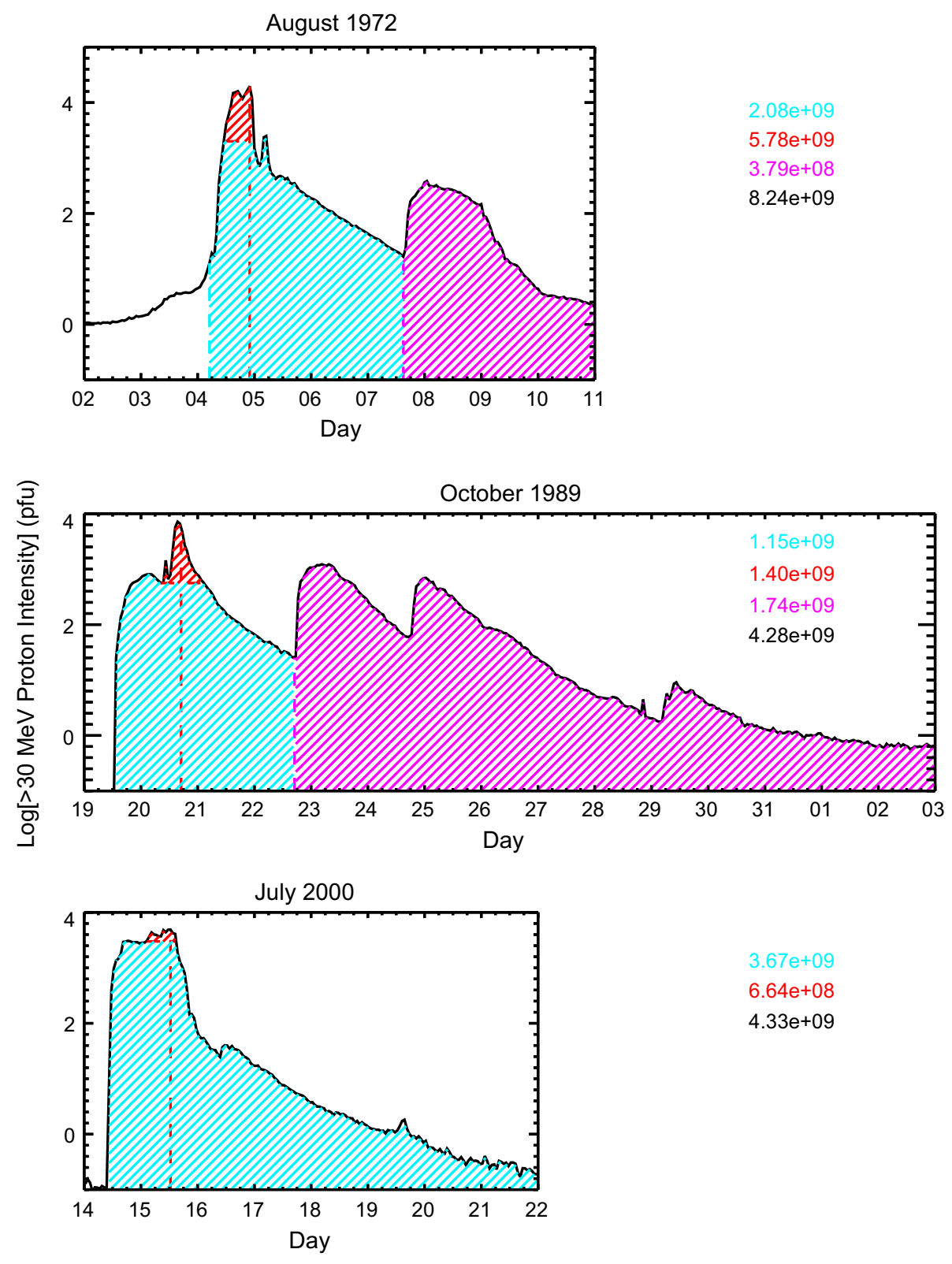

Fig. 16. Time-intensity profiles for large $F_{30}$ SEP events in August 1972, October 1989, and July 2000, showing in each case the contributions to the total event fluences from the initial (or only) major event (light blue cross-hatching), its shock peak (red), and subsequent events (purple). The dashed red vertical lines indicate the timing of the shock peaks. The color coded $>30 \mathrm{MeV}$ fluence values for each component are given

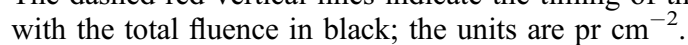

auroral/ionospheric component. The best evidence for such a low-latitude auroral effect is the simultaneous observation of a positive bay $(\Delta H=\sim 400 \mathrm{nT})$ in the magnetogram from Apia, Samoa $\left(15.3^{\circ} \mathrm{S}\right.$ geomagnetic latitude) in conjunction with the observation of an aurora from that site by Angenhesiter and Westland in May 1921 (Fig. 12). Various lines of evidence reviewed here (Figs. 5-10) indicate that a similar auroralinduced (negative) bay contributed to the negative spike in the Colaba trace in 1859. As Siscoe et al. (2006) pointed out, if the unprecedented negative excursion at Colaba in 1859 resulted from ionospheric currents, then "the fact that ionospheric currents could profoundly affect a magnetogram at such low latitude remains an exceptional aspect of the storm".

While we do not have any direct evidence of a SEP event associated with the August-September 1859 activity, either from nitrate or ${ }^{10} \mathrm{Be}$ concentration in ice cores, one almost certainly occurred. The best guess of its largest possible size based on modern data is that the $>30 \mathrm{MeV}$ fluence was $\sim 1.1 \times 10^{10} \mathrm{pr} \mathrm{cm}^{-2}$, about twice big as the strongest events observed during the modern era. This estimate assumes that a Carrington SEP event involved multiple eruptions and a shock spike (Smart et al. 2006a), similar to the composite events of August 1972 and October 1989 (Fig. 16). This appears to be the Sun's preferred way of making large $F_{30}$ events.

Acknowledgements. EWC is grateful to K. Harald Drager, President of The International Emergency Management Society, for organizing a conference on Space Weather and to Peter Stauning for the kind invitation to speak on super storms. He also thanks K. Schrijver and J. Beer for organizing a series of timely and stimulating ISSI workshops on extreme solar events. We thank Leif Svalgaard for 
helpful discussions and translating web material on the 1921 storm and Vera Svalgaard for translating the Secchi article. We thank the two referees for helpful comments and suggestions.

\section{References}

Akasofu, S.-I., and Y. Kamide, Comment on "The extreme magnetic storm of 1-2 September 1859" by B.T. Tsurutani, W.D. Gonzalez, G.S. Lakhina, and S. Alex, J. Geophys. Res., 110, A09226, DOI: 10.1029/2005JA011005, 2005.

Allen, J.A., L. Frank, H. Sauer, and P. Reiff, Effects of the March 1989 solar activity, Eos, Trans. Amer. Geophys. Union, 70, 1479, 1486-1488, 1989.

Angenheister, G., and C.J. Westland, The magnetic storm of May 13-14, 1921: observations at Samoa Observatory, New Zealand J. Sci. Tech., 4, 201-202, 1921.

Aulanier, G., P. Démoulin, C.J. Schrijver, M. Janvier, E. Pariat, and B. Schmieder, The standard flare model in three dimensions II. Upper limit on solar flare energy, $A \& A, \mathbf{5 4 9}, \mathrm{A} 66$, DOI: 10.1051/0004-6361/201220406, 2013.

Bartels, J., Solar eruptions and their ionospheric effects - a classical observation and its new interpretation, Terr. Mag. Atmos. Elect. 42, 235-239, 1937.

Beer, J., K. McCracken, and R. von Steiger, Cosmogenic Radionuclides: Theory and in the Terrestrial and Space Environments, Berlin, Springer, 2012.

Boteler, D.H., The super storms of August/September 1859 and their effects on the telegraph system, Adv. Space Res., 38, 159-172, 2006.

Botley, C.M., Some great tropical aurorae, J. Brit. Astron. Assoc., 67, 188-191, 1957.

Brodrick, D., S. Tingay, and M. Wieringa, X-ray magnitude of the 4 November 2003 solar flare inferred from the ionospheric attenuation of the galactic radio background, J. Geophys. Res., 110, A09S36, DOI: 10.1029/2004JA010960, 2005.

Brueckner, G.E., R.A. Howard, M.J. Koomen, C.M. Korendyke, and D.J. Michels, et al.,The Large Angle Spectroscopic Coronagraph (LASCO), Solar Phys., 162, 357-402, 1995.

Burton, R.K., R.L. Mcpherron, and C.T. Russell, An empirical relationship between interplanetary conditions and Dst, $J$. Geophys. Res., 80, 4204-4214, 1975.

Cane, H.V., D.V. Reames, and T.T. von Rosenvinge, The role of interplanetary shocks in the longitude distribution of solar energetic particles, J. Geophys. Res., 93, 9555-9567, 1988.

Carrington, R.C., Description of a singular appearance seen in the Sun on September 1, 1859, Mon. Not. Roy. Astron. Soc., 20, 13-14, 1860.

Challis, J., Observations at the Observatory at Cambridge, Greenwich Magnetical and Meteorological Observations, 226-227, 1847.

Clarke, E., C. Rodger, M. Clilverd, T. Humphries, O. Baillie, and A. Thomson, An estimation of the Carrington flare magnitude from solar flare effects (sfe) in the geomagnetic records2010. Royal Astron. Soc. National Astron. Meeting, 12-16 April, 2010 University of Glasgow, UK.

Cliver, E.W., The unusual relativistic solar proton events of 1979 August 21 and 1981 May 10, Astrophys. J., 639, 1206-1217, 2006a.

Cliver, E.W., The 1859 space weather event: then and now, $A d v$. Space Res., 38, 119-129, 2006b.

Cliver, E.W., and N.U. Crooker, A seasonal dependence for the geoeffectiveness of eruptive solar events, Solar Phys., 145 347-357, 1993

Cliver, E.W., and N.C. Keer, Richard Christopher Carrington: briefly among the great scientists of his time, Solar Phys., 280, 1-31, 2012.

Cliver, E.W., and L. Svalgaard, The 1859 solar-terrestrial disturbance and the current limits of extreme space weather activity, Solar Phys., 224, 407-422, 2004.
Cliver, E.W., S.W. Kahler, M.A. Shea, and D.F. Smart, Injection onsets of $2 \mathrm{GeV}$ protons, $1 \mathrm{MeV}$ electrons, and $100 \mathrm{keV}$ electrons in solar cosmic ray flares, Astrophys. J., 260, 362-370, 1982.

Cliver, E.W., J. Feynman, and H.B. Garrett, An estimate of the maximum speed of the solar wind, 1938-1989, J. Geophys. Res., 95, 17103-17112, 1990.

Cliver, E.W, K.S. Balasubramaniam, N.V. Nitta, and X. Li, Great geomagnetic storm of 9 November 1991: association with a disappearing solar filament, J. Geophys. Res., 114, A00A20, DOI: 10.1029/2008JA013232, 2009.

Cliver, E.W., A.G. Ling, A. Belov, and S. Yashiro, Size distributions of solar flares and solar energetic particle events, Astrophys. $J$. Lett., 756, L29, DOI: 10.1088/2041-8205/756/2/L29, 2012.

Cliver, E.W., A.J. Tylka, W.F. Dietrich, and A.G. Ling, On a solar origin for the cosmogenic nuclide event of $775 \mathrm{AD}$, Astrophys. $J$. Lett., Submitted, 2013.

Douglass, A.E., The aurora of May 14, 1921, Science, 54, 14, 1921. Emslie, G., B.R. Dennis, A.Y. Shih, P.C. Chamberlin, and R.A. Mewaldt, et al., Global energetics of thirty-eight large solar eruptive events, Astrophys. J., 759, 71, DOI: 10.1088/0004-637X/759/1/71, 2012.

Glaisher, J., Observations at the observatory at Cambridge, Greenwich Magnetical and Meteorological Observations, 222-223, 1847.

Gonzalez, W.D., E. Echer, A.L. Clúa de Gonzalez, B.T. Tsurutani, and G.S. Lakhina, Extreme geomagnetic storms recent Gleissberg cycles and space era-super intense storms, J. Atmos. Sol.-Terr. Phys., 73, 1447-1453, 2011.

Gopalswamy, N., L. Barbieri, E.W. Cliver, G. Lu, S.P. Plunkett, and R.M. Skoug, Introduction to violent Sun-Earth connection events of October-November 2003, J. Geophys. Res., 110, A09S15, DOI: 10.1029/2004JA010958, 2005a.

Gopalswamy, N., S. Yashiro, Y. Liu, G. Michalek, A. Vourlidas, M.L. Kaiser, and R.A. Howard, Coronal mass ejections and other extreme characteristics of the 2003 October-November solar eruptions, J. Geophys. Res., 110, A09S15,

DOI: $10.1029 / 2004 J A 010958,2005$ b.

Green, J.L., and S. Boardsen, Duration and extent of the great auroral storm of 1859, Adv. Space Res., 38, 130-135, 2006.

Hapgood, M.A., Towards a scientific understanding of the risk from extreme space weather, Adv. Space Res., 47, 2059-2072, 2011.

Hapgood, M.A., Prepare for the coming space weather storm, Nature, 484, 311-313, DOI: 10.1038/484311a, 2012.

Heikkilä, U., J. Beer, and J. Feichter, Meridional transport and deposition of atmospheric ${ }^{10} \mathrm{Be}$, Atmos. Chem. Phys., 9, 515-527, 2009.

Hodgson, R, On a curious appearance seen in the Sun, Mon. Not. Roy. Astron. Soc., 20, 15, 1860.

Jones, H.S., Royal Greenwich Observatory Sunspot and Geomagnetic Storm Data, London, Her Majesty's Stationery Office, 1955.

Kallenrode, M.-B., and E.W. Cliver, Rogue SEP events: modeling, in: Proc. 27th Int. Cosmic Ray Conf., 3318-3321, 2001.

Kane, S.R., K. Hurley, J.M. McTiernan, M. Sommer, M. Boer, and M. Niel, Energy release and dissipation during giant solar flares, Astrophys. J. Lett., 446, L47-50, 1995.

Kappenman, J.G., Great geomagnetic storms and impulsive geomagnetic field disturbance events - an analysis of observational evidence including the great storm of May 1921, Adv. Space Res., 38, 188-199, 2006.

Kiplinger, A.L., and H.A. Garcia, Soft X-ray parameters of the great flares of active region 486, Bull. Am. Astron. Soc., 36, 739, 2004.

Kretzschmar, M., The Sun as a star: observations of white-light flares, Astron. Astrophys., 530, A84, DOI: 10.1051/0004-6361/201015930, 2011.

Kretzschmar, M., T. Dudok de Wit, W. Schmutz, S. Mekaoui, J.-F. Hochedez, and S. Dewitte, The effect of flares on total solar irradiance, Nature Physics, 6, 690, DOI: 10.1038/NPHYS1741, 2010.

Lampland, C.O., Observations of the aurora at the Lowell observatory 14 May, 1921, Science, 54, 185-187, 1921.

Lario, D., and R.B. Decker, The energetic storm particle event of October 20, 1989, Geophys. Res. Lett., 29, 1393, DOI: 10.1029/2001GL014017, 2002. 
Li, X., M. Temerin, B.T. Tsurutani, and S. Alex, Modeling the 1-2 September 1859 super magnetic storm, Adv. Space Res., 38, 273$279,2006$.

Loomis, E., The great auroral exhibition of August 28th to September 4th 1859, Am. J. Sci. Arts, Second Series. 28, 385408, 1859, 29, 92-97, 249-266, 386-399, 1860; 79-100, 339361, 1860; 32, 71-84, 318-335, 1861.

Lundstedt, H., Solar storms and topology: observed with SDO, in: Proceedings of TIEMS conference "Space Weather and Challenges for Modern Society, 22-24 October, 2012.

Mayaud, P.N., Derivation, Meaning, and Use of Geomagnetic Indices, Geophys. Monograph Ser., vol. 22, Washington, DC, AGU, 1980.

McCracken, K.G., G.A.M. Dreschhoff, E.J. Zeller, D.F. Smart, and M.A. Shea, Solar cosmic ray events for the period 1561-1994: 1 . Identification in polar ice, 1561-1950, J. Geophys. Res., 106, 21585-21598, 2001a.

McCracken, K.G., G.A.M. Dreschhoff, D.F. Smart, and M.A. Shea, Solar cosmic ray events for the period 1561-1994: 2. The Gleissberg periodicity, J. Geophys. Res., 106, 21599-21609, $2001 \mathrm{~b}$.

Mewaldt, R.A., C.T. Russell, C.M.S. Cohen, A.B. Galvin, R. Gomez-Herrero, A. Klassen, R.A. Leske, J. Luhmann, G.M. Mason, and T.T. von Rosenvinge, A $360^{\circ}$ view of solar energetic particle events, including one extreme event, in: Proc. 33rd Int. Cosmic Ray Conf., 2013, in press.

O'Brien, T.P., and R.L. McPherron, An empirical phase space analysis of ring current dynamics: solar wind control of injection and decay, J. Geophys. Res., 105, 7707-7719, 2000.

Reedy, R.C., Solar proton fluxes since 1956, Proc. 8th Lunar Sci. Conf., 1, 825-839, 1977.

Riley, P., On the probability of occurrence of extreme space weather events, Space Weather, 10, S02012, DOI: 10.1029/2011SW000734, 2012.

Russell, H.N., Observations of the aurora at the Lowell Observatory 14 May, 1921, Science, 54, 184-184, 1921.

Russell, C.T., R.A. Mewaldt, J.G. Luhmann, G.M. Mason, and T.T. von Rosenvinge, et al., The very unusual interplanetary coronal mass ejection of July 23, 2012: a blast wave mediated by solar energetic particles, Astrophys. J. Lett., 770, 38-38, 2013.

Secchi, P., Sur les perturbations magnétiques observes à Rome le 2 Septembre 1859, Comptes Rendus, 49, 458-460, 1859.

Schrijver, C.J., J. Beer, U. Baltensperger, E.W. Cliver, and M. Güdel, et al., Estimating the frequency of extremely energetic solar events, based on solar, stellar, lunar, and terrestrial records, J. Geophys. Res., 117, A08103, DOI: 10.1029/2012JA017706, 2012.

Shea, M.A., and D.F. Smart, A summary of major solar proton events, Solar Phys., 127, 297-320, 1990.

Shea, M.A., and D.F. Smart, Compendium of the eight articles on the "Carrington Event" attributed to or written by Elias Loomis in the American Journal of Science, 1859-1861, Adv. Space Res., 38, 313-385, 2006.

Silverman, S.M., Low-latitude auroras: the great aurora of 4 February 1872, J. Atmos. Sol.-Terr. Phys., 70, 1301-1308, 2008.

Silverman, S.M., and E.W. Cliver, Low-latitude auroras: the magnetic storm of 14-15 May 1921, J. Atmos. Sol.-Terr. Phys., 63, 523-535, 2001.

Siscoe, G.L., N.U. Crooker, and L. Christopher, A solar cycle variation of the interplanetary magnetic field, Solar Phys., 56, 449-461, 1978.

Siscoe, G., N.U. Crooker, and C.R. Clauer, Dst of the Carrington storm of 1859, Adv. Space Res., 38, 173-179, 2006.

Slipher, V.M., Observations of the aurora at the Lowell observatory May 14, 1921, Science, 54, 184-185, 1921.

Smart, D.F., M.A. Shea, and K.G. McCracken, The Carrington event: possible solar proton intensity-time profile, Adv. Space Res., 38, 215-225, 2006.

Smart, D.F., M.A. Shea, H.E. Spence, and L. Kepko, Two groups of extremely large $>30 \mathrm{MeV}$ solar proton fluence events, Adv. Space Res., 37, 1734-1740, 2006.
Steljes, J.F., H. Carmichael, and K.G. McCracken, Characteristics and fine structure of the large cosmic-ray fluctuations in November 1960, J. Geophys. Res., 66, 1363-1377, 1961.

Stewart, B., On the great magnetic disturbance which extended from August 28 to September 7, 1859, as recorded by photography at Kew Observatory, Philos. Trans., 151, 423-430, 1861.

Sugiura, M., Hourly values of equatorial Dst for the IGY, Ann. Int. Geophys. Year, 35, 49, 1964.

Temerin, M., and X. Li, A new model for the prediction of Dst on the basis of the solar wind, J. Geophys. Res., 107, 1472, SMP 31-1. DOI: 10.1029/2001JA007532, 2002.

Temerin, M., and X. Li, Dst model for 1995-2002, J. Geophys. Res., 111, A04221, DOI: 10.1029/2005JA011257, 2006.

Thomson, N.R., C.J. Rodger, and R.L. Dowden, Ionosphere gives size of greatest solar flare, Geophys. Res. Lett., 31, L06803, DOI: 10.1029/2003GL019345, 2004.

Thomson, N.R., C.J. Rodger, and M.A. Clilverd, Large solar flares and their ionospheric D-region enhancements, J. Geophys. Res., 110, A06306, DOI: 10.1029/2005JA011008, 2005.

Tranquille, C., K. Hurley, and H.S. Hudson, The Ulysses catalog of solar hard X-ray flares, Solar Phys., 258, 141-166, 2009.

Tsurutani, B.T., W.D. Gonzalez, G.S Lakhina, and S. Alex, The extreme magnetic storm of 1-2 September 1859, J. Geophys. Res., 108, 12-68, SSH 1-1, DOI: 10.1029/2002JA009504, 2003.

Tsurutani, B.T., W.D. Gonzales, G.S. Lakhina, and S. Alex, Reply to comment by S.-I. Akasofu and Y. Kamide on "The extreme magnetic storm of 1-2 September 859", J. Geophys. Res., 110, A09227, DOI: 10.1029/2005JA011121, 2005.

Tyasto, M.I., N.G. Ptitsyna, I.S. Veselovsky, and O.S. Yakovchouk, Extremely strong geomagnetic storm of September 2-3, 1859, according to the archived data of observations at the Russian network, Geomag. Aeron., 49, 153-162, 2009.

Tylka, A., and W. Dietrich, M., Giller, and J. Szabelski, New and comprehensive analysis of proton spectra in ground level enhanced (GLE) solar particle events. In: Proc. 31th Int. Cosmic Ray Conf., Lodź, Poland, Universal Academy Press, ICRC0273, 2009.

Usoskin, I.G., and G.A. Kovaltsov, Occurrence of extreme solar particle events: assessment from historical proxy data, Astrophys. J., 757, 92, DOI: 10.1088/0004-637X/757/1/92, 2012.

Vallance Jones, A., Historical review of great auroras, Can. J. Phys., 70, 479-487, 1992.

Van Hollebeke, M.A., L.S. Ma Sung, and F.B. McDonald, The variation of solar proton energy spectra and size distribution with heliolongitude, Solar Phys., 41, 189-323, 1975.

Vasyliunas, V., The largest imaginable geomagnetic storm, J. Atmos. Sol.-Terr. Phys., 73, 1444-1446, 2011.

Veronig, A., M. Temmer, A. Hanslmeier, W. Otruba, and M. Messerotti, Temporal Aspects and frequency distributions of solar soft X-ray flares, Astron. Astrophys., 382, 1070-1080, 2002.

Westland, C.J., A note upon the Aurora Australis, J. Brit. Astron. Soc., 31, 380, 1921 .

Wolff, E.W., M. Bigler, M.A. J. Curran, J.E. Dibb, M.M. Frey, M. Legrand, and J.R. McConnell, The Carrington event not observed in most ice core nitrate records, Geophys. Res. Lett., 39, L08503, DOI: 10.1029/2012GL051603, 2012.

Woods, T.N., G. Kopp, P.C. Chamberlin, Contributions of the solar ultraviolet irradiance to the total solar irradiance during large flares, J. Geophys. Res., 111, A10S14, DOI: 10.1029/ 2005JA011507, 2006.

Yashiro, S., S. Akiyama, N. Gopalswamy, and R.A. Howard, Different power-law indices in the frequency distributions of flares with and without coronal mass ejections, Astrophys. J. Lett., 650, L143, DOI: 10.1086/508876, 2006.

Zhang, Z., I.G. Richardson, D.F. Webb, N. Gopalswamy, and E. Huttunen, et al., Solar and Interplanetary sources of major geomagnetic storms (Dst $\leq-100 \mathrm{nT}$ ) during 1996-2005, J. Geophys. Res., 112, A10102, DOI: 10.1029/2007JA012321, 2007.

Cite this article as: Cliver EW \& Dietrich WF: The 1859 space weather event revisited: limits of extreme activity. J. Space Weather Space Clim., 2013, 3, A31. 